\title{
Amelioration of Japanese encephalitis by blockage of 4-1BB signaling is coupled to divergent enhancement of type I/II IFN responses and Ly- $6 C^{\text {hi }}$ monocyte differentiation
}

Seong Bum Kim¹, Jin Young Choi', Jin Hyoung Kim', Erdenebelig Uyangaa', Ajit Mahadev Patil', Sang-Youel Park ${ }^{1,2}$, John Hwa Lee ${ }^{1,2}$, Koanhoi Kim³ ${ }^{3}$ Young Woo Han ${ }^{1}$ and Seong Kug Eo ${ }^{1,2^{*}}$

\begin{abstract}
Background: Japanese encephalitis (JE), a neuroinflammation caused by zoonotic JE virus, is the major cause of viral encephalitis worldwide and poses an increasing threat to global health and welfare. To date, however, there has been no report describing the regulation of JE progression using immunomodulatory tools for developing therapeutic strategies. We tested whether blocking the 4-1BB signaling pathway would regulate JE progression using murine JE model.

Methods: Infected wild-type and 4-1BB-knockout (KO) mice were examined daily for mortality and clinical signs, and neuroinflammation in the CNS was evaluated by infiltration of inflammatory leukocytes and cytokine expression. In addition, viral burden, JEV-specific T cell, and type I/II IFN (IFN-I/II) innate responses were analyzed.

Results: Blocking the 4-1BB signaling pathway significantly increased resistance to JE and reduced viral burden in extraneural tissues and the CNS, rather than causing a detrimental effect. In addition, treatment with 4-1BB agonistic antibody exacerbated JE. Furthermore, JE amelioration and reduction of viral burden by blocking the 4-1BB signaling pathway were associated with an increased frequency of IFN-II-producing NK and CD4 ${ }^{+}$Th1 cells as well as increased infiltration of mature Ly-6Chi monocytes in the inflamed CNS. More interestingly, DCs and macrophages derived from 4-1BB KO mice showed potent and rapid IFN-I innate immune responses upon JEV infection, which was coupled to strong induction of PRRs (RIG-I, MDA5), transcription factors (IRF7), and antiviral ISG genes (ISG49, ISG54, ISG56). Further, the ablation of 4-1BB signaling enhanced IFN-I innate responses in neuron cells, which likely regulated viral spread in the CNS. Finally, we confirmed that blocking the 4-1BB signaling pathway in myeloid cells derived from hematopoietic stem cells (HSCs) played a dominant role in ameliorating JE. In support of this finding, HSC-derived leukocytes played a dominant role in generating the IFN-I innate responses in the host.

(Continued on next page)
\end{abstract}

\footnotetext{
* Correspondence: vetvirus@chonbuk.ac.kr

${ }^{1}$ College of Veterinary Medicine and Bio-Safety Research Institute, Chonbuk

National University, Iksan 54596, Republic of Korea

2Department of Bioactive Material Sciences, Graduate School, Chonbuk

National University, Jeonju 54896, Republic of Korea

Full list of author information is available at the end of the article
}

C Biomed Central

(c) 2015 Kim et al. Open Access This article is distributed under the terms of the Creative Commons Attribution 4.0 International License (http://creativecommons.org/licenses/by/4.0/), which permits unrestricted use, distribution, and reproduction in any medium, provided you give appropriate credit to the original author(s) and the source, provide a link to the Creative Commons license, and indicate if changes were made. The Creative Commons Public Domain Dedication waiver (http://creativecommons.org/publicdomain/zero/1.0/) applies to the data made available in this article, unless otherwise stated. 
(Continued from previous page)

Conclusions: Blocking the 4-1BB signaling pathway ameliorates JE via divergent enhancement of IFN-II-producing NK and CD4 ${ }^{+}$Th1 cells and mature Ly-6Chi monocyte infiltration, as well as an IFN-I innate response of myeloid-derived cells. Therefore, regulation of the 4-1BB signaling pathway with antibodies or inhibitors could be a valuable therapeutic strategy for the treatment of JE.

Keywords: 4-1BB signal, Japanese encephalitis, Type I/II IFN, Ly-6Chi monocytes, Zoonotic diseases, Neurologic disorder

\section{Background}

The incidence of zoonotic diseases transmitted to humans from wild or domestic animals has increased noticeably during the past few decades and currently represents at least $70 \%$ of emerging diseases [1]. Japanese encephalitis virus (JEV), a zoonotic, mosquito-borne Flavivirus, is considered to be a major cause of viral encephalitis worldwide. Due to rapid changes in climate and demography, vectortransmitted JEV poses an increasing threat to global health and welfare with approximately 67,900 cases reported annually, despite large, effective immunization campaigns [2-4]. The incubation period of JE ranges from 5 to 15 days and JEV infections are lethal in about 25-30 \% of cases, mostly in infants, and cause permanent neuropsychiatric sequelae in $50 \%$ of cases [4]. Accordingly, JE is considered to be more fatal than West Nile (WN) encephalitis, which results in a fatality in 3-5\% of cases (1100 deaths/29,000 symptomatic infections) [5]. Currently, more than $60 \%$ of the world's population inhabits JE endemic areas, including eastern and southern Asia, and the virus is spreading to previously unaffected regions, such as Indonesia, Pakistan, and northern Australia [2, 3].

JE is a neuroinflammation characterized by extensive CNS inflammation and disruption of the blood-brain barrier (BBB) after zoonotic JEV infection. Considerable progress in understanding the kinetics and mechanisms of JEV dissemination and JE pathogenesis has been made in murine models [6-8]. However, the molecular pathogenesis of JE remains elusive. After peripheral introduction of the virus via mosquito bites, JEV initially replicates in primary target cells, such as dendritic cells (DCs) and macrophages, at the periphery and subsequently gains entry into the CNS through the BBB. While JEV infects and kills neurons directly in the CNS, CNS invasion by JEV also drives the stimulation of microglia/glia and infiltrated leukocytes, leading to indirect death of neuron cells via secretion of pro-inflammatory cytokines (such as IL-6 and TNF- $\alpha$ ) and soluble mediators $[9,10]$. Therefore, JE is considered an immunopathological disease in which uncontrolled over-activation of innate and adaptive immune cells drives neurological disorders in the CNS such as paralysis. While JEV-specific $\mathrm{T}$ cells and virus-neutralizing IgM and IgG are considered to participate in the clearance of virus from both peripheral lymphoid tissues and the CNS [11], innate immune responses appear to play a more crucial role in the early control of JEV infection, due to delayed establishment of adaptive immunity. The type I IFN (IFN-I; typically IFN- $\alpha / \beta$ ) innate immune response is essential for controlling various viral infections, including JEV [12-15], and IFN-I production is triggered by recognition of viral pathogen-associated molecular patterns (PAMPs) through cytoplasmic helicases (RIG-I, MDA5) and Toll-like receptors (TLRs) [16-20]. In addition, recent data indicate that type II IFN (IFN-II; only member IFN$\gamma)$ produced by $\mathrm{NK}$ and $\mathrm{CD}_{4}^{+}$Th1 cells has a beneficial effect on disease outcomes after JEV infection [21, 22], although the requirement for IFN-II in recovery from infection with different flaviviruses varies [21, 23-29].

Recently, the debatable role of CD $11 b^{+}$Ly $-6 C^{\text {hi }}$ monocytes in the course of neuroinflammation caused by pathogenic $\mathrm{CD}^{+} \mathrm{T}$ cells or neurotropic viruses has initiated a new era in the exploration of their differentiation lineage and immunopathological role in the CNS [30]. These Ly$6 \mathrm{C}^{\text {hi }}$ monocytes migrate into the infected CNS, where they differentiate into DCs, macrophages, and arguably microglia to regulate neuroinflammation [30-32]. Despite the conflicting results of studies investigating the role of Ly$6 \mathrm{C}^{\mathrm{hi}}$ monocytes in modulating neuroinflammation, CNS infiltration by CD $11 b^{+}$Ly- $6 C^{\text {hi }}$ monocytes is required for the control of neuroinflammation, which supports their protective role during CNS inflammation [33-36]. Notably, the differentiation levels of Ly- $6 C^{\text {hi }}$ monocytes that infiltrate into the CNS appear to affect the progression of neuroinflammation caused by various insults [37-39]. However, restraint of CNS infiltration of leukocytes from the periphery, including innate and adaptive immune cells, is also required because hematogenous inflammation causes profound damage if the reaction is excessive or uncontrollable [40]. Therefore, a clear understanding of the regulation of excessive and uncontrollable immune responses during JE progression is needed to ameliorate the progression of neuroinflammation without tissue damage.

4-1BB (CD137) is a member of the tumor necrosis factor receptor (TNFR) superfamily, and its role as a T cell costimulatory molecule has been well defined [41]. However, 4-1BB molecules are also expressed on a variety of innate immune cells, including NK cells, DCs, monocytes, and neutrophils [42-46]. Stimulation of the 4-1BB signal is believed to enhance protective immune responses against 
pathogens, because agonistic anti-4-1BB mAbs can enhance the efficacy of vaccines against influenza and poxvirus $[47,48]$. The importance of the 4-1BB receptor-ligand system in viral infection control is further supported by the fact that 4-1BB ligand-deficient mice exhibit impaired immunity against lymphocytic choriomeningitis virus (LCMV) [49] and a few influenza virus strains [50,51]. At the same time, stimulation of the 4-1BB signal pathway with agonistic mAbs also inhibits the development of several autoimmune diseases, including lupus, arthritis, and experimental autoimmune encephalomyelitis [52-54], which indicates that there must be contradictory effects from the stimulation of the 4-1BB receptor-ligand system. Therefore, it is likely that 4-1BB signaling plays different roles depending on the properties of diseases: mild vs. severe forms or pathogenic vs. autoimmunogenic. Despite various and seemingly contradictory roles of the 4-1BB receptor-ligand system in various inflammatory diseases, $4-1 \mathrm{BB}$ is still an attractive target for the development of therapeutic strategies for incurable inflammatory diseases. However, no reports have yet shown the regulatory effect of the 4-1BB signaling pathway on neuroinflammation caused by neurotropic viruses such as JEV. In this study, somewhat surprisingly, blocking the 4-1BB signaling pathway ameliorated JE progression, rather than causing detrimental effects. Furthermore, the protective role of blocking the 4-1BB signal against JE was likely mediated by enhanced IFN-I innate immune responses in myeloidderived and neuron cells, an increased number of IFN- $\gamma$-producing NK and $\mathrm{CD} 4^{+}$Th1 cells, and early and increased infiltration of mature Ly- $6 \mathrm{C}^{\text {hi }}$ monocytes in the CNS. Therefore, our data provide valuable insight into the regulation of the 4-1BB signaling pathway as a therapeutic target for neuroinflammation caused by infection with flaviviruses such as JEV and West Nile virus (WNV).

\section{Methods}

\section{Ethics statement}

All animal experiments were conducted at Chonbuk National University according to guidelines set by the Institutional Animal Care and Use Committees (IACUC) of Chonbuk National University (http://lac.honamlife.com) and were pre-approved by the Ethical Committee for Animal Experiments of Chonbuk National University (Permission code 2013-0028). The animal research protocol in this study followed the guidelines set up by the nationally recognized Korea Association for Laboratory Animal Sciences (KALAS). All experimental protocols requiring biosafety were approved by Institutional Biosafety Committees (IBC) of Chonbuk National University.

\section{Animals, cells, and viruses}

C57BL/6 (H-2 $\left.{ }^{\text {b }}\right)$ mice (4-5 weeks old) were purchased from Samtako (O-San, Korea). 4-1BB (H-2 $\left.{ }^{\mathrm{b}}\right)$ knockout (KO) mice were obtained from Ulsan University. All mice were genotyped and bred in the animal facilities of Chonbuk National University. JEV Beijing-1 strain was obtained from the Green Cross Research Institute (Suwon, Korea) and propagated in the mosquito cell line C6/36 using DMEM supplemented with $2 \% \mathrm{FBS}$, penicillin $(100 \mathrm{U} / \mathrm{ml})$, and streptomycin $(100 \mathrm{U} / \mathrm{ml})$. C6/36 cultures were infected with JEV Beijing-1 at a multiplicity of infection (MOI) of 0.1 and were incubated in a humidified $\mathrm{CO}_{2}$ incubator for $1 \mathrm{~h}$ at $28{ }^{\circ} \mathrm{C}$. After absorption, the inoculum was removed, and $7 \mathrm{ml}$ of a maintenance medium containing $2 \%$ FBS was added. Approximately 6-7 days postinfection (dpi), cultures of host cells showing an 80-90\% cytopathic effect were harvested. Virus stocks were titrated using either a conventional plaque assay or a focus-forming assay and were stored in aliquots at $-80{ }^{\circ} \mathrm{C}$ until use.

\section{Antibodies and reagents}

The following mAbs used for flow cytometric analysis and other experiments were obtained from eBioscience (San Diego, CA, USA) or R\&D Systems (Minneapolis, MN, USA): fluorescein isothiocyanate (FITC) conjugatedanti-CD4 (RM4-5), CD8 (53-6.7), CD40 (HM40-3), CD44 (IM7), CD80 (16-10A1), CD86 (GL1), F4/80 (8 M8), MHC I (28-14-8), MHC II (M5/114.15.2), and Ly-6G (1A8); phycoerythrin (PE) conjugated-anti-mouse-CD11b (M1/70), Foxp3 (FJK-16 s), CD154(MR1), CCR2 (475301), CXCR2 (242216), and granzyme B (NGZB); peridinin chlorophyll protein complex (PerCP) conjugate-anti-Ly-6C (HK1.4); PE-Cyanine dye (Cy5.5)-anti-mouse IFN- $\gamma$ (XMG1.2); PE-Cyanine dye (Cy7)-anti-mouse NK1.1 (PK136); and allophycocyanin (APC) conjugated-antimouse-CD25 (PC62.5), Ly-6G (Gr-1), TNF- $\alpha$ (MP6-XT22), and IL-17A (eBio17B7). Peptides of I-A $\mathrm{A}^{\mathrm{b}}$-restricted epitopes (JEV NS1 $1_{132-145}$ [TFVVDGPETKECPD] and NS3 ${ }_{563-574}$ [WCFDGPRTNAIL]) and $\mathrm{H}-2 \mathrm{D}^{\mathrm{b}}$-restricted epitope (JEV $\mathrm{NS} \mathrm{B}_{215-223}$ [SAVWNSTTA]) were chemically synthesized at Peptron Inc. (Daejeon, Korea). JEV-specific primers for the detection of viral RNA (JEV10,564-10,583 forward, 5'-CCC TCA GAA CCG TCT CGG AA-3' and JEV10,86210,886 reverse, 5' -CTA TTC CCA GGT GTC AAT ATG CTG T-3') and primers specific for cytokines, type I IFNs $($ IFN- $\alpha / \beta)$, and RLRs, IRFs, ISGs (Table 1 ) were synthesized at Bioneer Corp. (Daejeon, Korea) and used for PCR amplification of target genes.

\section{Quantitative real-time RT-PCR for viral burden and cytokine expression}

Viral burden and cytokine (TNF- $\alpha$, IFN- $\alpha$, and IFN- $\beta$ ) expression in inflammatory and lymphoid tissues were determined by conducting quantitative SYBR Green-based 
Table 1 Specific primers for cytokine, type I IFNs, PRRs, IRFs, and ISGs used in real-time qRT-PCR

\begin{tabular}{|c|c|c|c|}
\hline Gene name $^{a}$ & Primer sequence $\left(5^{\prime}-3^{\prime}\right)^{\mathrm{b}}$ & Position cDNA & Gene Bank ID \\
\hline \multirow[t]{2}{*}{ TNF-a } & FP: CGT CGT AGC AAA CCA CCA AG & $438-457$ & \multirow[t]{2}{*}{ NM_013693 } \\
\hline & RP: TTG AAG AGA ACC TGG GAG TAG ACA & $564-587$ & \\
\hline \multirow[t]{2}{*}{ IFN- $a$} & FP: TGTCTGATGCAGCAGGTGG & $367-385$ & \multirow[t]{2}{*}{ NM_008334.3 } \\
\hline & RP: AAGACAGGGCTCTCCAGAC & $514-532$ & \\
\hline \multirow[t]{2}{*}{ IFN- $\beta$} & FP: TCCAAGAAAGGACGAACATTCG & $106-121$ & \multirow[t]{2}{*}{ NM_010510 } \\
\hline & RP: TGAGGACATCTCCCACGTCAA & $399-419$ & \\
\hline \multirow[t]{2}{*}{ IRF3 } & FP: GAT GGA GAG GTC CAC AAG GA & 1170-1189 & \multirow[t]{2}{*}{ NM_016849 } \\
\hline & RP: GAG TGT AGC GTG GGG AGT GT & $1259-1278$ & \\
\hline \multirow[t]{2}{*}{ IRF7 } & FP: CCT CTT GCT TCA GGT TCT GC & 980-999 & \multirow[t]{2}{*}{ NM_016850.3 } \\
\hline & RP: GCT GCA TAG GGT TCC TCG TA & 1080-1099 & \\
\hline \multirow[t]{2}{*}{ RIG-I } & FP: CCA CCT ACA TCC TCA GCT ACA TGA & $194-217$ & \multirow[t]{2}{*}{ NM_172689 } \\
\hline & RP: TGG GCC CTT GTT GTT CTT CT & $260-279$ & \\
\hline \multirow[t]{2}{*}{ MDA5 } & FP: GGC ACC ATG GGA AGT GAT T & 1178-1196 & \multirow[t]{2}{*}{ NM_027835 } \\
\hline & RP: ATT TGG TAA GGC CTG AGC TG & $1247-1266$ & \\
\hline \multirow[t]{2}{*}{ ISG49 } & FP: GCC GTT ACA GGG AAA TAC TGG & 919-939 & \multirow[t]{2}{*}{ NM_010501.2 } \\
\hline & RP: CCT CAA CAT CGG GGC TCT & $1126-1143$ & \\
\hline \multirow[t]{2}{*}{ ISG54 } & FP: GGG AAA GCA GAG GAA ATC AA & 1918-1937 & \multirow[t]{2}{*}{ NM_008332.3 } \\
\hline & RP: TGA AAG TTG CCA TAC AGA AG & $2005-2024$ & \\
\hline \multirow[t]{2}{*}{ ISG56 } & FP: CAG AAG CAC ACA TTG AAG AA & 774-793 & \multirow[t]{2}{*}{ NM_008331.3 } \\
\hline & RP: TGT AAG TAG CCA GAG GAA GG & $911-930$ & \\
\hline \multirow[t]{2}{*}{$\beta$-Actin } & FP: TGG AAT CCC TGT GGG ACC ATG AAA C & $885-909$ & \multirow[t]{2}{*}{ NM_007393.3 } \\
\hline & RP: TAA AAC GCA GCT CAG TAA CAG TCC G & $1209-1233$ & \\
\hline
\end{tabular}

a IL interleukin, TNF- $a$ tumor necrosis factor- $a$, IFN interferon

${ }^{\mathrm{b}} \mathrm{FP}$ forward primer, $R P$ reverse primer

real-time RT-PCR (real-time qRT-PCR). Mice were infected intraperitoneally (i.p.) with JEV $\left(3.0 \times 10^{7} \mathrm{PFU}\right)$ and tissues including the brain, spinal cord, and spleen were harvested at 2, 4, and 6 dpi following extensive cardiac perfusion with Hanks balanced salt solution (HBSS). Total RNA was extracted from tissues using easyBLUE (iNtRON, INC., Daejeon, Korea) and subjected to real-time qRT-PCR using a CFX96 Real-Time PCR Detection system (Bio-Rad Laboratories, Hercules, CA, USA). Following reverse transcription of total RNA with High-Capacity cDNA Reverse Transcription Kits (Applied Biosystems, Foster, CA, USA), the reaction mixture contained $2 \mu \mathrm{l}$ of template cDNA, $10 \mu \mathrm{l}$ of $2 \times$ SYBR Primix Ex Taq, and $200 \mathrm{nM}$ primers for a final volume of $20 \mu \mathrm{l}$. The reactions were denatured at $95{ }^{\circ} \mathrm{C}$ for $30 \mathrm{~s}$ and then subjected to 45 cycles of $95{ }^{\circ} \mathrm{C}$ for $5 \mathrm{~s}$ and $60{ }^{\circ} \mathrm{C}$ for $20 \mathrm{~s}$. After the reaction cycle was complete, the temperature was increased from 65 to $95{ }^{\circ} \mathrm{C}$ at a rate of $0.2{ }^{\circ} \mathrm{C} / 15 \mathrm{~s}$, and the fluorescence was measured every $5 \mathrm{~s}$ to construct a melting curve. A control sample that contained no template DNA was run with each assay, and all determinations were performed at least in duplicate to ensure reproducibility. The authenticity of the amplified product was determined by melting curve analysis. All data were analyzed using the Bio-Rad CFX Manager, version 2.1 analysis software (Bio-Rad Laboratories).

\section{Analysis and activation of NK cells}

The activation of NK cells was assessed by the capacity to produce IFN- $\gamma$ and granzyme B (GrB) following brief stimulation with PMA and ionomycin (Sigma-Aldrich). Splenocytes were prepared from BL/6 and 4-1BB KO mice $2 \mathrm{dpi}$ and stimulated with PMA $(50 \mathrm{ng} / \mathrm{ml})$ and ionomycin $(750 \mathrm{ng} / \mathrm{ml})$ in the presence of monensin $(2 \mu \mathrm{M})$ to induce the expression of IFN- $\gamma$ and GrB for 1 and $2 \mathrm{~h}$, respectively. After stimulation, cells were surface stained by FITC anti-mouse-CD3ع, PE-Cy7 anti-mouse NK1.1, and biotinconjugated anti-mouse pan-NK cell (CD49b) [DX5] antibodies and streptavidin-APC for $30 \mathrm{~min}$ at $4{ }^{\circ} \mathrm{C}$. The cells were then washed twice with FACs buffer containing monensin. After fixation, cells were permeabilized with $1 \times$ permeabilization buffer (eBioscience) and stained intracellularly with PE anti-mouse IFN- $\gamma$ (XMF1.2) and GrB antibodies (NGZB) in permeabilization buffer for 30 min at $4{ }^{\circ} \mathrm{C}$. Finally, the cells were washed with PBS twice, and analysis was performed with FACS Calibur 
flow cytometer (Becton Dickson Medical Systems, Sharon, MA, USA) and FlowJo software (ver. 7.6.5; Tree Star, San Carlos, CA, USA).

\section{JEV-specific $\mathrm{CD}^{+}$and $\mathrm{CD}^{+}{ }^{+} \mathrm{T}$ cell responses}

JEV-specific $\mathrm{CD} 4^{+}$and $\mathrm{CD} 8^{+} \mathrm{T}$ cell responses were determined by intracellular CD154 $[55,56]$ as well as IFN- $\gamma$ and TNF- $\alpha$ staining in response to stimulation with respective JEV epitope peptides. Surviving mice infected with JEV $\left(3.0 \times 10^{7} \mathrm{PFU}\right)$ were sacrificed at 7 or $14 \mathrm{dpi}$, and splenocytes were prepared. The erythrocytes were depleted by treating single-cell suspensions with ammonium chloride-containing Tris buffer $\left(\mathrm{NH}_{4} \mathrm{Cl}\right.$-Tris $)$ for $5 \mathrm{~min}$ at $37{ }^{\circ} \mathrm{C}$. The splenocytes were cultured in 96-well culture plates $\left(5 \times 10^{5}\right.$ cells/well $)$ in the presence of synthetic peptide epitopes ( $\mathrm{NS}_{132-145}, \mathrm{NS}_{563-574}$, and $\mathrm{NS}_{53} \mathrm{~B}_{215-225}$ ) for 12 and $6 \mathrm{~h}$, in order to observe $\mathrm{CD} 4^{+}$and $\mathrm{CD} 8^{+} \mathrm{T}$ cell responses, respectively. Monensin $(2 \mu \mathrm{M})$ was added to antigen-stimulated cells $6 \mathrm{~h}$ before harvest. The cells were washed twice with PBS and surface stained with FITCanti-CD4 or CD8 antibodies for $30 \mathrm{~min}$ at $4{ }^{\circ} \mathrm{C}$ and then washed twice with PBS containing monensin again. After fixation, the cells were washed twice with permeabilization buffer (eBioscience) and stained with PE Cy5.5-anti-IFN- $\gamma$ or APC-anti-TNF- $\alpha$ in permeabilization buffer for $30 \mathrm{~min}$ at room temperature. Intracellular CD154 was detected by the addition of CD154 mAb in the culture media during peptide stimulation. Finally, the cells were washed twice with PBS and fixed using a fixation buffer. Sample analysis was performed with FACS Calibur flow cytometer (Becton Dickson Medical Systems) and FlowJo (Tree Star) software.

\section{Intracellular staining for analysis of $\mathrm{CD} 4^{+} \mathrm{Th} 1, \mathrm{Th} 17$, and Treg cells}

To monitor $\mathrm{CD}^{+}{ }^{+}$Th subsets, mice infected with JEV $\left(3.0 \times 10^{7} \mathrm{PFU}\right)$ were sacrificed at 3 and $5 \mathrm{dpi}$, and splenocytes were prepared. Splenocytes were cultured in 96well culture plates $\left(10^{6}\right.$ cells/well $)$ with PMA $(50 \mathrm{ng} / \mathrm{ml})$ plus ionomycin $(750 \mathrm{ng} / \mathrm{ml})$ in the presence of monensin $(2 \mu \mathrm{M})$ for $5 \mathrm{~h}$ at $37^{\circ} \mathrm{C}$. The stimulated cells were washed twice with PBS and surface stained with FITC-anti-CD4 for $30 \mathrm{~min}$ at $4{ }^{\circ} \mathrm{C}$ and then washed twice with PBS containing monensin. After fixation, the cells were washed twice with permeabilization buffer (eBioscience) and stained with PerCP-anti-IFN- $\gamma$ and APC-anti-IL-17 $\alpha$ in permeabilization buffer for $30 \mathrm{~min}$ at room temperature. Finally, the cells were washed twice with PBS and fixed using fixation buffer. To monitor Treg cells, splenocytes were surface stained for FITC-anti-CD4 markers for $30 \mathrm{~min}$ on ice and then fixed with fixation/ permeabilization concentrate buffer (eBioscience) for $6 \mathrm{~h}$ at $4{ }^{\circ} \mathrm{C}$. After fixation, the cells were washed twice with permeabilization buffer and stained with PE-anti-Foxp3 in permeabilization buffer for $30 \mathrm{~min}$ at room temperature. The sample analysis was performed with FACS Calibur flow cytometer.

\section{Analysis of leukocytes infiltrated into the CNS}

Mice infected with JEV were perfused with $30 \mathrm{ml}$ of HBSS at 2 or 4 dpi via cardiac puncture of the left ventricle. Brains were then harvested and homogenized by gently pressing them through a 100 -mesh tissue sieve, after which they were digested with $25 \mu \mathrm{g} / \mathrm{ml}$ of collagenase type IV (Worthington Biochem, Freehold, NJ, USA), $0.1 \mu \mathrm{g} / \mathrm{ml}$ trypsin inhibitor $N \alpha$ - $p$-tosyl-L-lysine chloromethyl ketone, $10 \mu \mathrm{g} / \mathrm{ml}$ DNase I (Amresco, Solon, OH, USA), and $10 \mathrm{mM}$ HEPE in HBSS for $1 \mathrm{~h}$ at $37^{\circ} \mathrm{C}$, under shaking conditions. Cells were separated by using an Optiprep density gradient $(18 / 10 / 5 \%)$ centrifugation at $800 \times \mathrm{g}$ for $30 \mathrm{~min}$ (Axis-Shield, Oslo, Norway), after which cells were collected from the 18 to $10 \%$ interface and washed twice with PBS. Cells were counted and stained for CD11b, Ly6G, Ly6C, F4/80, and MHC II with directly conjugated antibodies (eBioscience) for $30 \mathrm{~min}$ at $4{ }^{\circ} \mathrm{C}$. Finally, the cells were fixed with $10 \%$ formaldehyde. Data collection and analysis were performed with FACS Calibur flow cytometer (Becton Dickson Medical Systems) and FlowJo (Tree Star) software.

\section{Primary cell culture and infection Myeloid-derived DCs and macrophages}

Bone-marrow derived DCs (BMDC) and macrophages (BMDM) were prepared from bone marrow cells of 4-1BB $\mathrm{KO}$ and WT mice. In order to prepare BMDC, bone marrow cells $\left(3 \times 10^{5}\right.$ cells $\left./ \mathrm{ml}\right)$ from femurs and tibiae were cultured in RPMI 1640 supplemented with $2 \mathrm{ng} / \mathrm{ml} \mathrm{GM-}$ CSF and $10 \mathrm{ng} / \mathrm{ml} \mathrm{IL}-4$. On day 3, another $6 \mathrm{ml}$ of fresh complete medium containing $2 \mathrm{ng} / \mathrm{ml}$ GM-CSF and $10 \mathrm{ng} / \mathrm{ml} \mathrm{IL-4}$ was added, and half of the medium was changed on day 6 . On day 8 , non-adherent and loosely adherent DCs were harvested by vigorous pipetting. Cells were then characterized by flow cytometric analysis, which revealed that the culture generally consisted of

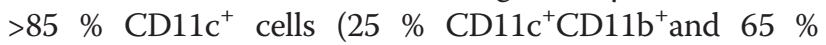
$\left.\mathrm{CD} 11 \mathrm{c}^{+} \mathrm{CD} 8 \alpha^{+}\right)$. BMDM were prepared by culturing bone marrow cells in DMEM supplemented with 30 \% L929 cellconditioned medium (LCCM) as a source of macrophagecolony-stimulating factor (M-CSF). On day 3, another $6 \mathrm{ml}$ of fresh complete medium containing $30 \%$ LCCM was added, and half of the medium was changed on day 6 . The cultured cells were harvested following an 8-day incubation and analyzed by flow cytometry. The prepared BMDM were composed of $>85 \% \mathrm{~F} 4 / 80^{+}$cells that consisted of $99.2 \% \mathrm{~F} 4 / 80^{+} \mathrm{CD} 11 \mathrm{~b}^{+}$and $\sim 1 \% \mathrm{~F} 4 / 80^{+} \mathrm{CD} 11 \mathrm{c}^{+}$cells. Prepared BMDC and BMDM were infected with JEV at 
MOIs of 1.0 and 10 for viral replication and $10 \mathrm{MOI}$ for cytokine expression.

\section{Primary cortical neurons}

Primary cortical neurons were prepared from 15-day-old embryos. Cortical neurons were seeded in 12-well polyD-lysine/laminin-coated plates in DMEM containing $5 \%$ FBS and $5 \%$ horse serum for $24 \mathrm{~h}$ and then cultured for 4 days with neurobasal medium containing B27 supplement and L-glutamine (Invitrogen, Carlsbad, CA, USA). Primary cortical neurons were infected with JEV at a 0.1 MOI for viral replication and type I IFN responses.

\section{Generation of BM chimeric mice and determination of serum IFN- $\beta$}

C57BL/6 mice (5-week-old) and 4-1BB KO mice were $\gamma$ irradiated with one dose of 900 rads. Within $12 \mathrm{~h}$, recipient mice were reconstituted with $10^{7}$ donor BM cells derived from $\mathrm{C} 57 \mathrm{BL} / 6$ and $4-1 \mathrm{BB} \mathrm{KO}$ mice. The recipient mice were given sulfamethoxazole and trimethoprim in their drinking water for 10 days after irradiation. Mice were infected with JEV 4-6 weeks after irradiation. A commercial ELISA kit (PBL Biomedical Laboratories, Piscataway, NJ, USA) was used to measure levels of secreted IFN- $\beta$ protein in the sera, according to the manufacturer's protocol.

\section{Statistical analysis}

All data were expressed as the average \pm standard deviation, and statistically significant differences between groups were analyzed by unpaired two-tailed Student's $t$ tests for ex vivo experiments and immune cell analysis or ANOVA and post hoc test for multiple comparisons of the mean. The statistical significance of viral burden was evaluated by Mann-Whitney test or unpaired two-tailed Student's $t$ test. Kaplan-Meier survival curves were analyzed with the log-rank test. A $p$ value $\leq 0.05$ was considered significant. All data were analyzed using Prism software (GraphPadPrism4, San Diego, CA, USA).

\section{Results}

\section{Blocking 4-1BB signaling ameliorates JE}

Blocking or triggering the 4-1BB signaling pathway has been shown to elicit various and seemingly contradictory results in the regulation of inflammatory diseases, depending on the severity of the disease model [47-54]. Furthermore, the role of the 4-1BB signaling pathway in modulating neuroinflammation caused by neurotropic viruses has been not addressed to date. Therefore, we tested whether blocking 4-1BB signaling would modulate neuroinflammation caused by JEV infection, in order to evaluate the therapeutic potential of the 4-1BB signaling pathway in JE progression. To this end, we examined and compared the susceptibility of 4-1BB-deficient (4-
1BB KO) mice to JE caused by neurotropic JEV infection with that of wild-type (WT) BL/6 mice (Fig. 1a). Interestingly, ablation of 4-1BB signaling provided significantly enhanced resistance to JE after infection with two different JEV doses $\left(p=0.012\right.$ for $1.5 \times 10^{7}$ and $p=0.002$ for $3.0 \times 10^{7} \mathrm{PFU}$ ). Likewise, 4-1BB KO mice showed delayed signs of neurological disorders starting from 5 to 6 $\mathrm{dpi}$, whereas BL/6 mice showed neurological disorders more quickly and at a higher proportion (Fig. 1b). In addition, 4-1BB ablation resulted in less change in body weight (Fig. 1c). These results indicate that ablation of 4-1BB signaling ameliorated JE progression.

This finding prompted us to investigate whether stimulation of the 4-1BB signaling pathway would affect the severity of JE. 3E1 mAb has been used as an agonistic antibody to stimulate 4-1BB signaling in a variety of immune cells, including $\mathrm{T}$ cells, dendritic cells (DCs), and NK cells [42-44]. Treatment with agonistic 3E1 mAb significantly reduced the survival of mice with JE and induced faster and enhanced proportions of neurological disorders (Fig. 1d), indicating that stimulating 4-1BB signaling exacerbates JE progression. This result strengthens our finding that blocking 4-1BB signaling provides enhanced resistance to JE. To better understand JE progression in 4-1BB KO mice, we examined the viral burden in peripheral lymphoid and CNS tissues after JEV infection. 4-1BB KO mice were found to contain 10- to 100-fold less virus in the spleen, brain, and spinal cord compared to BL/6 mice (Fig. 1e). Collectively, these results suggest that ablation of 4-1BB signaling ameliorates JE progression by regulating viral burden, while triggering 4-1BB signaling enhances the severity of JE.

\section{Enhancement of innate NK cell responses in 4-1BB signal-ablated mice}

4-1BB and its ligand are expressed in innate immune cells as well as BM cells, and attempts to evaluate the regulation of myelopoiesis by the 4-1BB receptor-ligand system have yielded conflicting results [42-54]. Furthermore, signaling in the 4-1BB receptor-ligand system is thought to be bidirectional, where 4-1BB and its ligand are expressed as transmembrane proteins on the cell surface and transmit signals into both cells [57]. Therefore, activation of the 4-1BB ligand in APCs may contribute to the elimination of pathogens by enhancing its APC activity. However, since 4-1BB deficiency may induce the abrogation of 4-1BB ligand signaling during JE progression, JE amelioration in 4-1BB $\mathrm{KO}$ mice may occur through other mechanisms. To investigate the mechanisms behind our results, we examined innate immune responses in 4-1BB KO mice upon JEV infection. Our results revealed that JEV infection of 4-1BB KO mice induced no significant alterations in DC subpopulations $\left(\mathrm{CD} 11 \mathrm{c}^{\mathrm{hi}} \mathrm{CD} 11 \mathrm{~b}^{+}\right.$myeloid, CD11c ${ }^{\mathrm{hi}} \mathrm{CD} 8 \alpha^{+}$lymphoid, and 

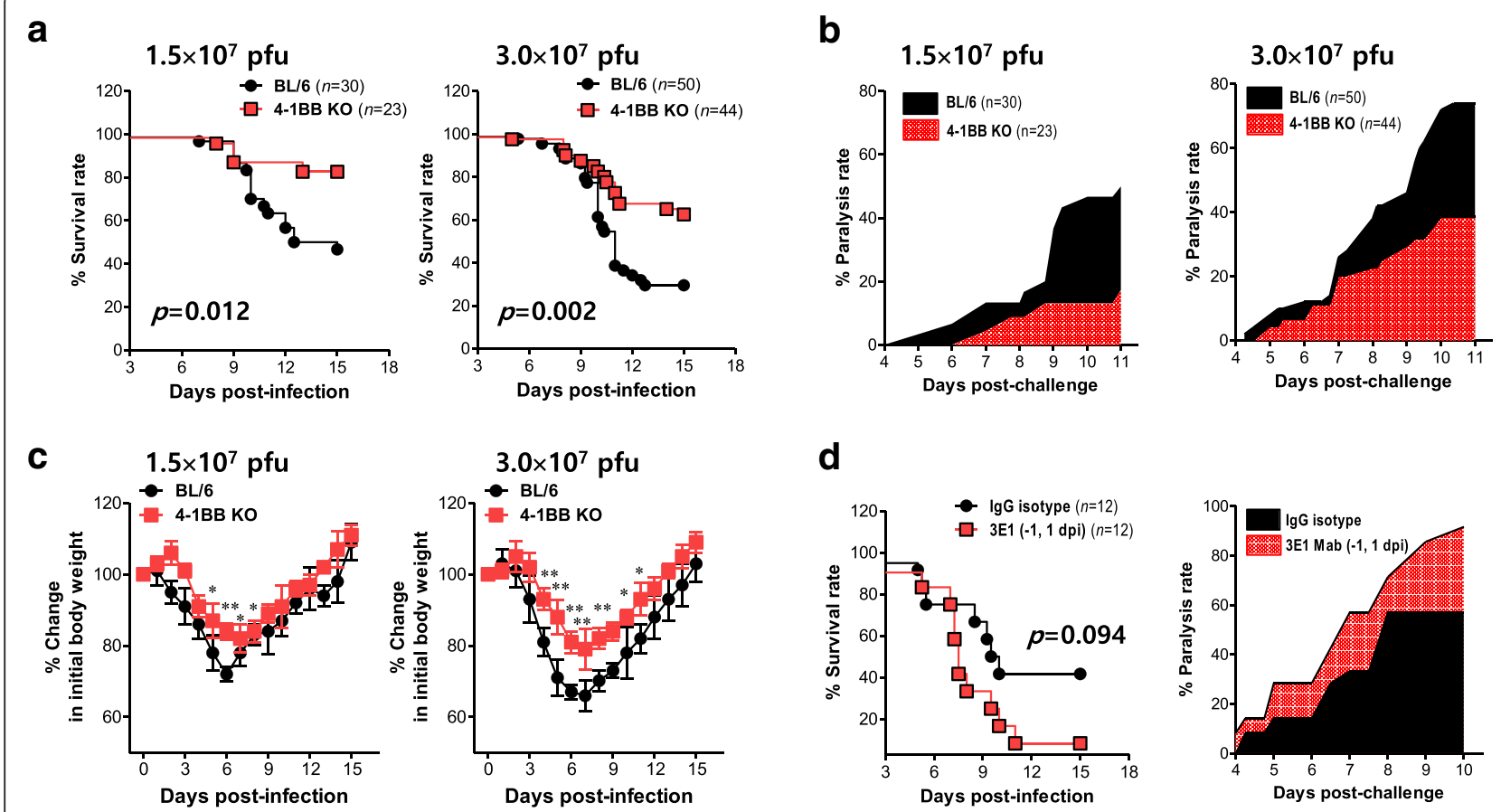

d
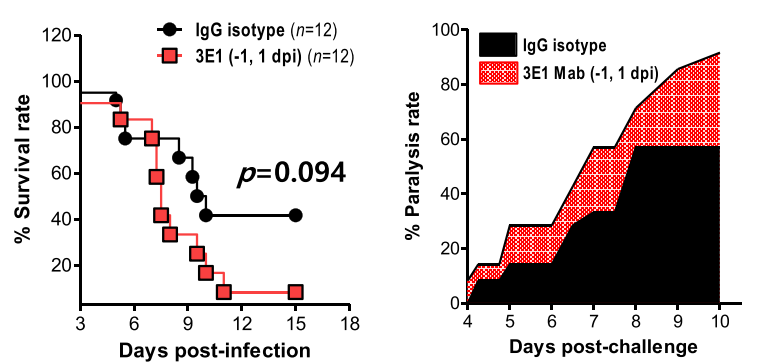

$\mathbf{e}$
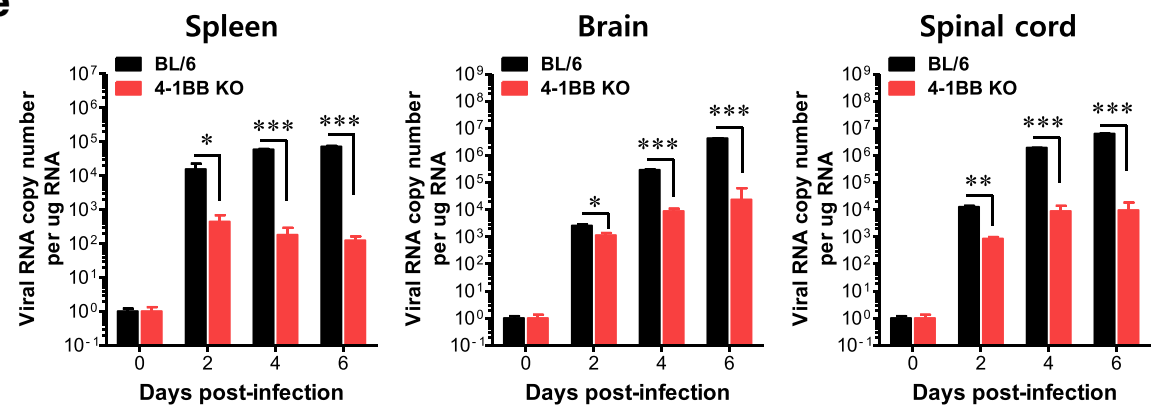

Fig. 1 Blocking the 4-1BB signaling pathway ameliorates JE along with a reduction in viral burden. a Susceptibility of 4-1BB KO mice to JE. BL/6 and 4-1BB KO mice (4- to 5-week-old, $n=23-50$ ) were inoculated i.p. with JEV (1.5 or 3.0 $10^{7} \mathrm{PFU}$ ), and the survival rate was examined over 15 days. b Ratio of mice showing neurological disorder during JE progression. Mice infected with JEV were examined every $6 \mathrm{~h}$ from 4 to $11 \mathrm{dpi}$, and the ratio of mice showing neurological disorder in inoculated mice was recorded. c Changes in body weight. Changes in body weight are expressed as the average percentage \pm SD of body weight relative to the time of challenge. $\mathbf{d}$ Exacerbation of JE by 4-1BB signal stimulation. WT mice were intravenously given an agonistic antibody (3E1, $400 \mu \mathrm{g} / \mathrm{mouse}$ ) to the 4-1BB signal at -1 and 1 dpi and examined for survival and paralysis rate. e Viral burden in lymphoid and inflammatory tissues during JE. Viral burden in the spleen, brain, and spinal cord of infected mice was assessed by real-time qRT-PCR at the indicated dpi. The viral RNA load is expressed by viral RNA copy number per microgram of total RNA $(n=5-7) .{ }^{*} p<0.05 ;{ }^{* *} p<0.01 ;{ }^{* *} p<0.001$ compared with the levels of the indicated groups

CD11 ${ }^{\text {int }}$ PDCA-1 ${ }^{\text {hi }}$ plasmacytoid DC) (Fig. 2a). However, 4-1BB KO mice showed basally higher frequencies and numbers of $\mathrm{CD}^{-} \mathrm{NK} 1.1^{+} \mathrm{DX} 5^{+} \mathrm{NK}$ cells compared to BL/ 6 mice. Subsequently, the frequencies and number of NK cells were markedly enhanced in 4-1BB KO mice following JEV infection (Fig. 2b), indicating that 4-1BB signaling may interfere with the development of NK cells in wildtype BL/6 mice during JE progression. In addition, 4-1BB KO mice showed enhanced activity of NK cells upon JEV infection when evaluated by enumeration of NK cells producing IFN- $\gamma$ and granzyme $B$ in response to stimulation of PMA plus ionomycin (Fig. 2c). This result implies that the enhancement of innate NK cell immune responses in 4-1BB $\mathrm{KO}$ mice may contribute to increased resistance to JE.

Impaired T-cell-mediated adaptive immunity in 4-1BB signal-ablated mice following JEV

Although recent results suggest complex roles for the 4$1 \mathrm{BB}$ signal pathway in modulating $\mathrm{T}$ cell responses, 4-1BB signaling is considered a positive regulator of $\mathrm{T}$ cell responses against pathogens $[47,48]$. Therefore, we examined the generation of JEV-specific $\mathrm{CD}^{+}$and $\mathrm{CD} 8^{+} \mathrm{T}$ cell responses in surviving $\mathrm{BL} / 6$ and 4-1BB $\mathrm{KO}$ mice at 7 dpi. 
a
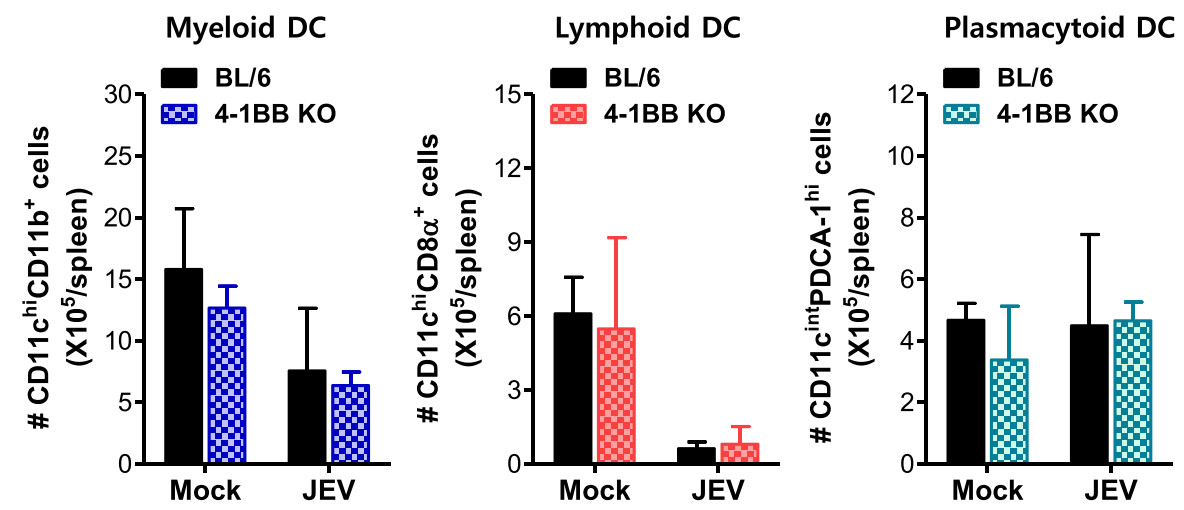

b

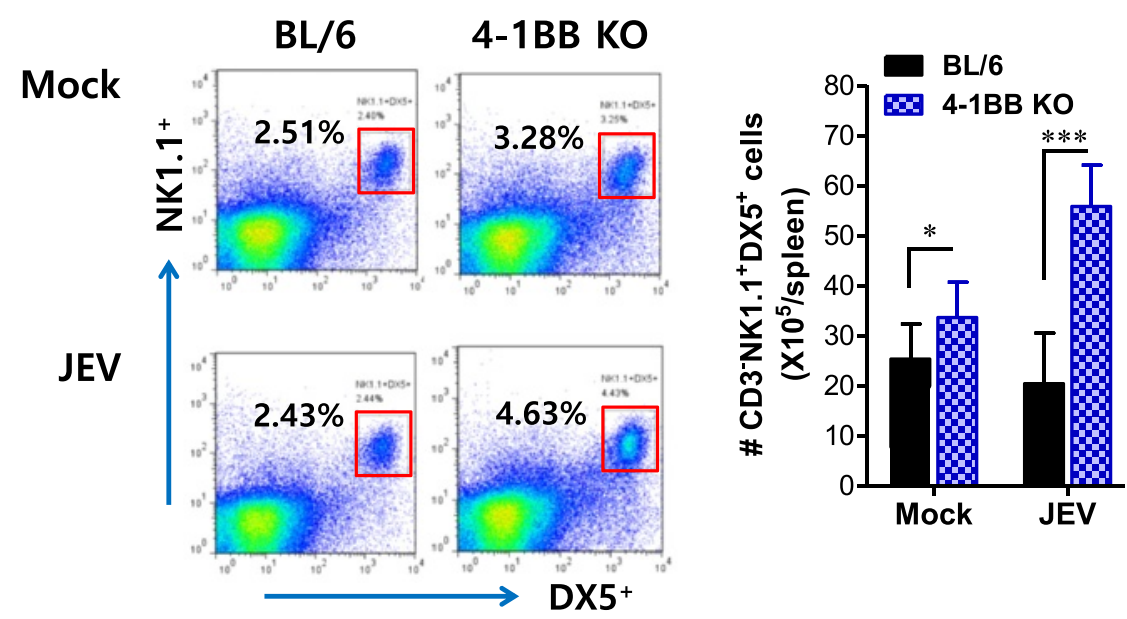

C
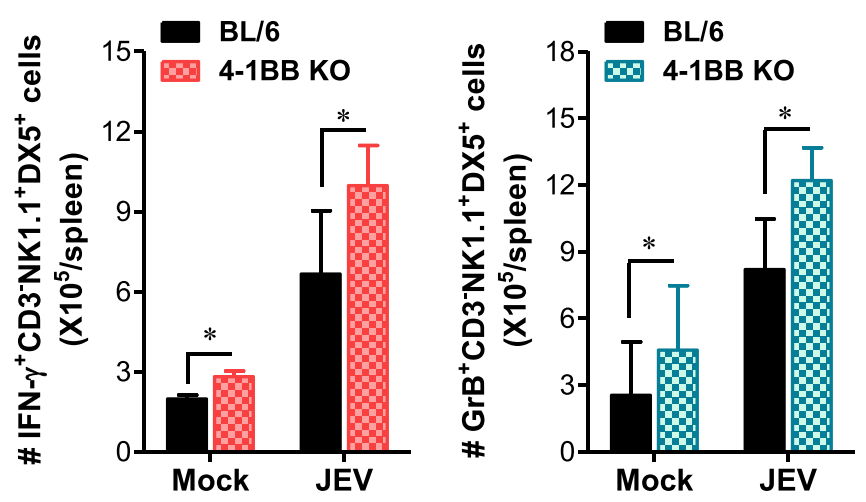

Fig. 2 Enhanced development of innate NK cell responses in 4-1BB signal-ablated mice. a Absolute number of DC subpopulations. DC subpopulations (myeloid, lymphoid, and plasmacytoid DCs) were enumerated by flow cytometric analysis using collagenase-treated spleen 2 dpi. b Frequency and absolute number of NK cells. The frequency and number of $C D 3^{-} \mathrm{NK} 1.1^{+} \mathrm{DX} 5^{+} \mathrm{NK}$ cells were determined 2 dpi. Values in representative dot-plots denote the average percentage of NK cells after gating on CD3-negative cells. $\mathbf{c}$ NK cell activation. The activation of NK cells was evaluated by enumerating NK cells producing IFN- $\gamma$ and granzyme B (GrB) using intracellular cytokine staining 2 dpi. Bar graphs show the average \pm SD of values derived from at least four mice per group. ${ }^{*} p<0.05 ;{ }^{* *} p<0.01 ;{ }^{* * *} p<0.001$ compared with the levels of the indicated groups

As expected, our results revealed that ablation of the 4$1 \mathrm{BB}$ signal induced a reduction in $\mathrm{CD} 4^{+} \mathrm{T}$ cell responses specific for two epitopes ( $\mathrm{NS}_{132-145}$ and $\mathrm{NS}_{563-574}$ ) derived from JEV Ag (Fig. 3a, b), based on enumeration of JEV-specific $\mathrm{CD} 4^{+} \mathrm{T}$ cells by intracellular CD154 staining $[55,56]$. In addition, the total number of $\mathrm{CD} 4^{+}$ 


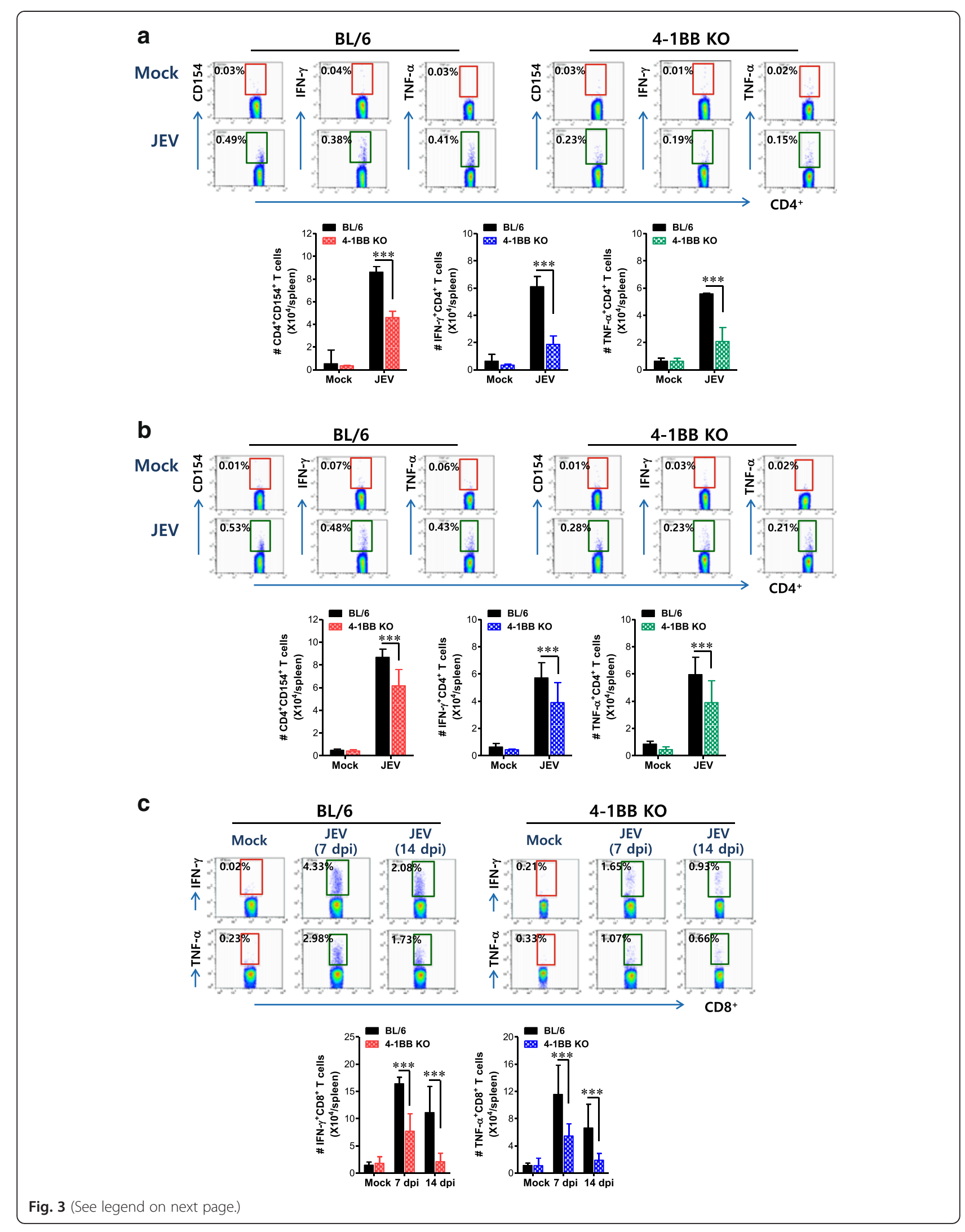


(See figure on previous page.)

Fig. 3 Impaired JEV-specific T cell immunity in 4-1BB signal-ablated mice. a, b JEV-specific CD4 ${ }^{+} \mathrm{T}$ cell responses. c JEV-specific CD8 ${ }^{+} \mathrm{T}$ cell responses. Splenocytes prepared from surviving mice at 7 or 14 dpi were stimulated with JEV epitope peptide of CD4 ${ }^{+}$T cells (a NS1 $132-145 ; \mathbf{b}$ NS3 $_{563-574}$ ) or CD $8^{+}$ T cells (NS4B $215-223$ ) for 12 or 6 h, respectively. The frequency and absolute number of JEV-specific CD4 ${ }^{+}$and CD8 ${ }^{+} T$ cells were determined by intracellular CD154 and cytokine (IFN- $\gamma$ and TNF-a) staining, combined with surface CD4 and CD8 staining. Values in representative dot-plots denote the average percentage of the indicated cell population, and bar charts show the average \pm SD of values derived from at least four mice per group. ${ }^{*} p<0.05$; ${ }^{* *} p<0.01 ;{ }^{* * *} p<0.001$ compared with the levels of the indicated groups

T cells producing IFN- $\gamma$ and TNF- $\alpha$ in response to epitope peptide stimulation was lower in 4-1BB $\mathrm{KO}$ mice than in $\mathrm{BL} / 6$ mice. In particular, JEV-specific $\mathrm{CD}^{+} \mathrm{T}$ cell responses were 2- to 4-fold lower in 4-1BB KO mice than in BL/6 mice, based on $\mathrm{CD}^{+} \mathrm{T}$ cells producing IFN- $\gamma$ and TNF- $\alpha$ upon stimulation with $\mathrm{CD}^{+} \mathrm{T}$ cell epitope (NS4B $\left.\mathrm{B}_{215-223}\right)$ (Fig. 3c). Collectively, considering that adequate $\mathrm{CD} 4^{+}$ and $\mathrm{CD}^{+} \mathrm{T}$ cell responses may contribute to the regulation of JE progression [21, 22], these results suggest that impaired $\mathrm{CD}^{+}$and $\mathrm{CD}^{+} \mathrm{T}$ cell responses generated in 4-1BB $\mathrm{KO}$ mice are not involved in conferring enhanced resistance to JE.

\section{A skewed response of 4-1BB-ablated mice to IFN- $\gamma$ - producing $\mathrm{CD}^{+}$Th1 during JE}

$\mathrm{CD} 4^{+} \mathrm{CD} 25^{+} \mathrm{Foxp}^{+}$Treg cells may contribute to the control of neuroinflammation caused by neurotropic viruses [58]. Moreover, 4-1BB signaling has been reported to alter the balance between $\mathrm{CD} 4^{+} \mathrm{CD} 25^{+}$Foxp $3^{+}$Treg and $\mathrm{IL}-17^{+} \mathrm{CD} 4^{+}$Th17 cells during inflammatory reactions [59]. In order to investigate additional mechanisms, we also addressed the frequency and number of CD4 ${ }^{+} \mathrm{CD}_{25}{ }^{+} \mathrm{Foxp}^{+}$Treg cells during JE progression. There was no apparent alteration of the number or frequency of $\mathrm{CD} 4{ }^{+} \mathrm{CD} 25^{+}$Foxp $^{+}$Treg cells in 4-1BB KO mice during JE progression (Fig. 4a). However, more CD4 ${ }^{+}$Th1 cells producing IFN- $\gamma$ were detected in 4-1BB-ablated mice, and decreased frequency and number of IL-17 ${ }^{+} \mathrm{CD} 4{ }^{+}$Th17 cells were observed in both BL/6 and 41BB KO mice during JE progression (Fig. 4b). This result indicates that the increase in IFN $-\gamma^{+} \mathrm{CD} 4^{+} \mathrm{Th} 1$ cells, but not $\mathrm{CD}_{4}^{+} \mathrm{CD} 25^{+}$Foxp $3^{+}$Treg or $\mathrm{IL}-17^{+} \mathrm{CD} 4^{+}$Th17 cells, is closely associated with enhanced resistance of $4-1 \mathrm{BB}$ KO mice against JE.

\section{Enhanced CNS infiltration of matured Ly- $6 C^{\text {hi }}$ monocytes in 4-1BB signal-ablated mice}

CNS-infiltration of CD11b $\mathrm{b}^{+} \mathrm{L}-6 \mathrm{C}^{\mathrm{hi}}$ monocytes is a hallmark of neuroinflammation caused by neurotropic viral infection [30]. Although the role of CD11b ${ }^{+}$Ly $-6 C^{\text {hi }}$ monocytes is debatable in the progression of neuroinflammation, CNS infiltration and maturation of CD11b $b^{+} \mathrm{Ly}-6 \mathrm{C}^{\text {hi }}$ monocytes are believed to support their protective role during neuroinflammation [33-36]. Accordingly, we examined the frequency and total number of CD $11 b^{+} L y-6 C^{\text {hi }}$ monocytes during JE progression to investigate their role in enhanced resistance of 4-1BB KO mice to JE. Wild-type $\mathrm{BL} / 6$ and 4-1BB $\mathrm{KO}$ mice showed comparable levels of CD11b ${ }^{+}$Ly- $6 C^{\text {hi }}$ monocytes in the spleen and blood before JEV infection, but the frequency and absolute number of CD $11 b^{+}$Ly-6C ${ }^{\text {hi }}$ monocytes increased in the spleen and blood of 4-1BB KO mice during JE progression (Fig. 5a-c). Consistently, 4-1BB KO mice displayed early and increased

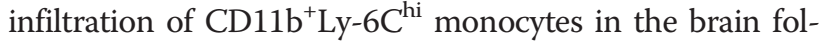
lowing JEV infection, compared to BL/6 mice (Fig. 5d), and the total number of $\mathrm{CD} 11 \mathrm{~b}^{+}$myeloid cells and CD11b ${ }^{+} \mathrm{Ly}-6 \mathrm{C}^{\mathrm{hi}}$ monocytes was also higher in the brain of $4-1 \mathrm{BB}$ $\mathrm{KO}$ mice (Fig. 5e). However, there were no differences in the total number of CD $11 b^{+}$Ly- $6 G^{\text {hi }}$ granulocytes that had infiltrated into the brain of 4-1BB KO mice compared to $\mathrm{BL} / 6$ mice. It has been shown that microglia cells contribute to the pathogenesis of neuroinflammation caused by some neurotropic viruses such as WNV [31]. Thus, triplecolor staining (CD11c/CD11b/CD45) was used to distinguish between resting and activated microglia. Based on the CNS myeloid cell classification of Ford et al. [60], the absolute number of both resting $\left(\mathrm{CD} 11 \mathrm{c}^{-} \mathrm{CD} 11 \mathrm{~b}^{\text {hi }} \mathrm{C}\right.$ $\left.\mathrm{D} 45^{\text {int }}\right)$ and activated microglia $\left(\mathrm{CD} 11 \mathrm{c}^{-} \mathrm{CD} 11 \mathrm{~b}^{\text {hi }} \mathrm{CD} 45^{\mathrm{hi}}\right)$ increased 2- to 3-fold in 4-1BB KO mice compared to BL/ 6 mice (Fig. 5f).

To further determine whether the maturation of CD11b ${ }^{+}$Ly-6C ${ }^{\text {hi }}$ monocytes could be affected by 4-1BB signal ablation, we characterized the phenotypic levels of splenic CD11b ${ }^{+}$Ly- $6 C^{\text {hi }}$ monocytes. Phenotypic levels of CD11b ${ }^{+}$Ly-6C ${ }^{\text {hi }}$ monocytes in uninfected 4-1BB $\mathrm{KO}$ mice were not significantly different from those of uninfected BL/6 mice. However, CD11b ${ }^{+}$Ly- $6 C^{\text {hi }}$ monocytes in the spleen of 4-1BB KO mice displayed more matured phenotypes following JEV infection than did BL/6 mice (Fig. 5g). Notably, F4/80, a phenotypic marker of mature macrophages, was expressed at much higher levels in $\mathrm{CD} 11 \mathrm{~b}^{+} \mathrm{Ly}-6 \mathrm{C}^{\mathrm{hi}}$ monocytes that had infiltrated into the brain of 4-1BB KO mice compared to those of BL/6 mice (Fig. 5h). Consistently, activated microglia $\left(\mathrm{CD} 11 \mathrm{c}^{-} \mathrm{CD} 11 \mathrm{~b}^{\mathrm{hi}} \mathrm{CD} 45^{\mathrm{hi}}\right)$ in the brains of 4-1BB $\mathrm{KO}$ mice showed higher expression of MHC II molecules than those of BL/6 mice (Fig. 5i), as one marker of microglia activation $[61,62]$. Collectively, these results suggest that early and increased infiltration of mature CD $11 b^{+}$Ly- $6 C^{\text {hi }}$ monocytes in the CNS could be involved in the enhanced resistance of 4-1BB-ablated mice to JE. 


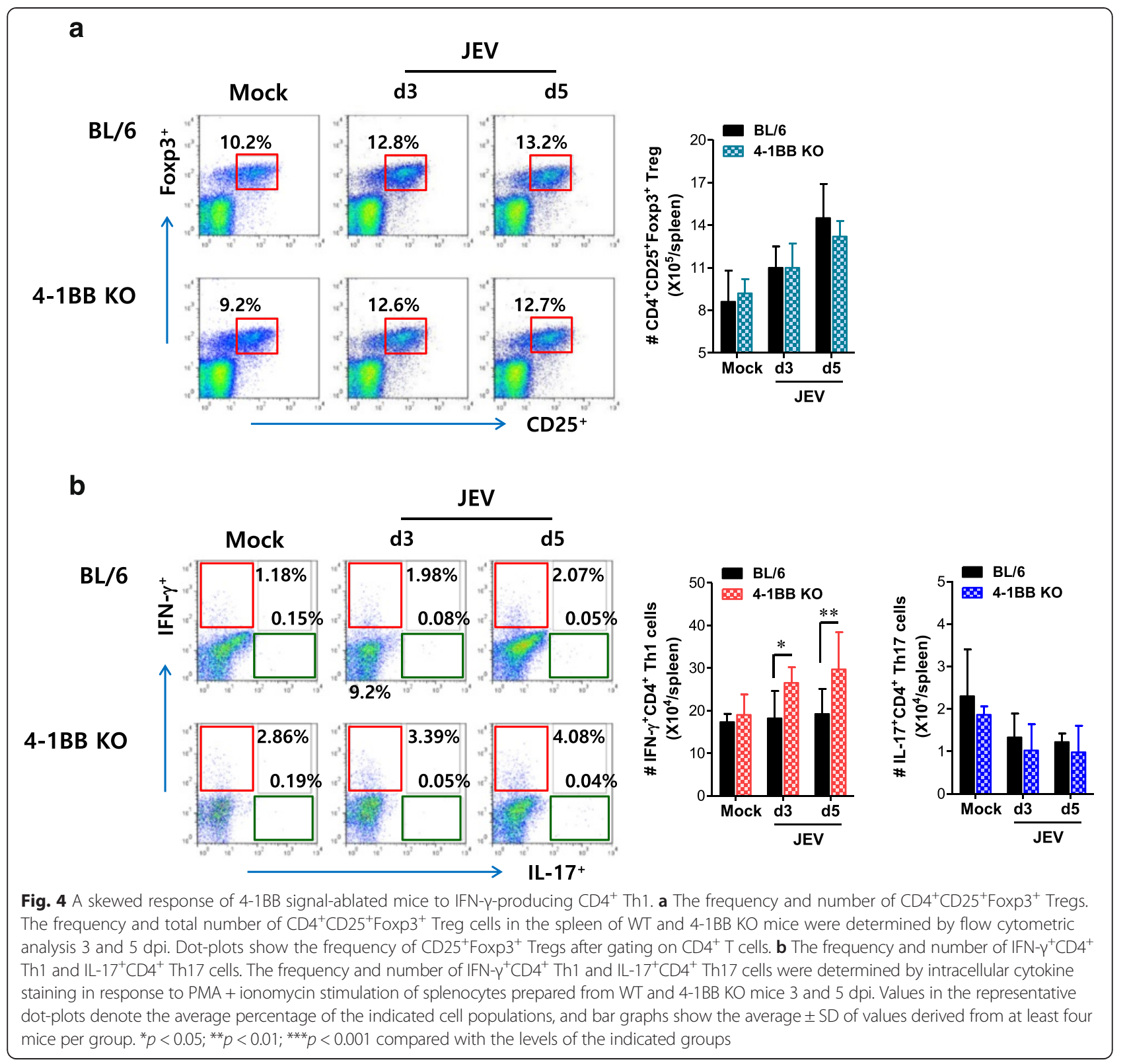

\section{Potent IFN-I innate response of 4-1BB signal-deficient} myeloid cells controls JEV replication

Myeloid cells, including both tissue and lymphoid DCs and macrophages, are primary target cells for JEV infection and regulate the spread of a virus to distant tissues such as the CNS [7, 8]. In addition, myeloid cells can produce IFN-I proteins $(\mathrm{IFN}-\alpha / \beta)$ via PRR recognition upon JEV infection, which plays a crucial role in controlling viral replication at the periphery [16-20]. Because virus load at the periphery of 4-1BB $\mathrm{KO}$ mice was lower than that of wild-type BL/6 mice in the present study, we assessed whether 4-1BB signaling would affect JEV replication and IFN-I innate response in myeloidderived cells as primary target cells, in order to further define the role of 4-1BB signaling in controlling JE progression. Bone marrow-derived DCs (BMDC) and macrophages (BMDM) of 4-1BB $\mathrm{KO}$ mice were infected with JEV and used to evaluate viral replication and the induction of IFN-I and pro-inflammatory cytokines. Interestingly, 4-1BB-deficient BMDC sustained significantly lower JEV replication throughout the examination period compared to wild-type BMDC infected with JEV (1.0 and $10 \mathrm{MOI}$ ) (Fig. 6a). Similarly, BMDM obtained from 4-1BB KO mice also showed less JEV replication (Fig. 6b). In support of these findings, the inhibition of JEV replication in 4-1BB-deficient BMDC and BMDM was closely associated with potently enhanced expression of IFN-I (IFN- $\beta$ ) following JEV infection (Fig. 6c, d). 


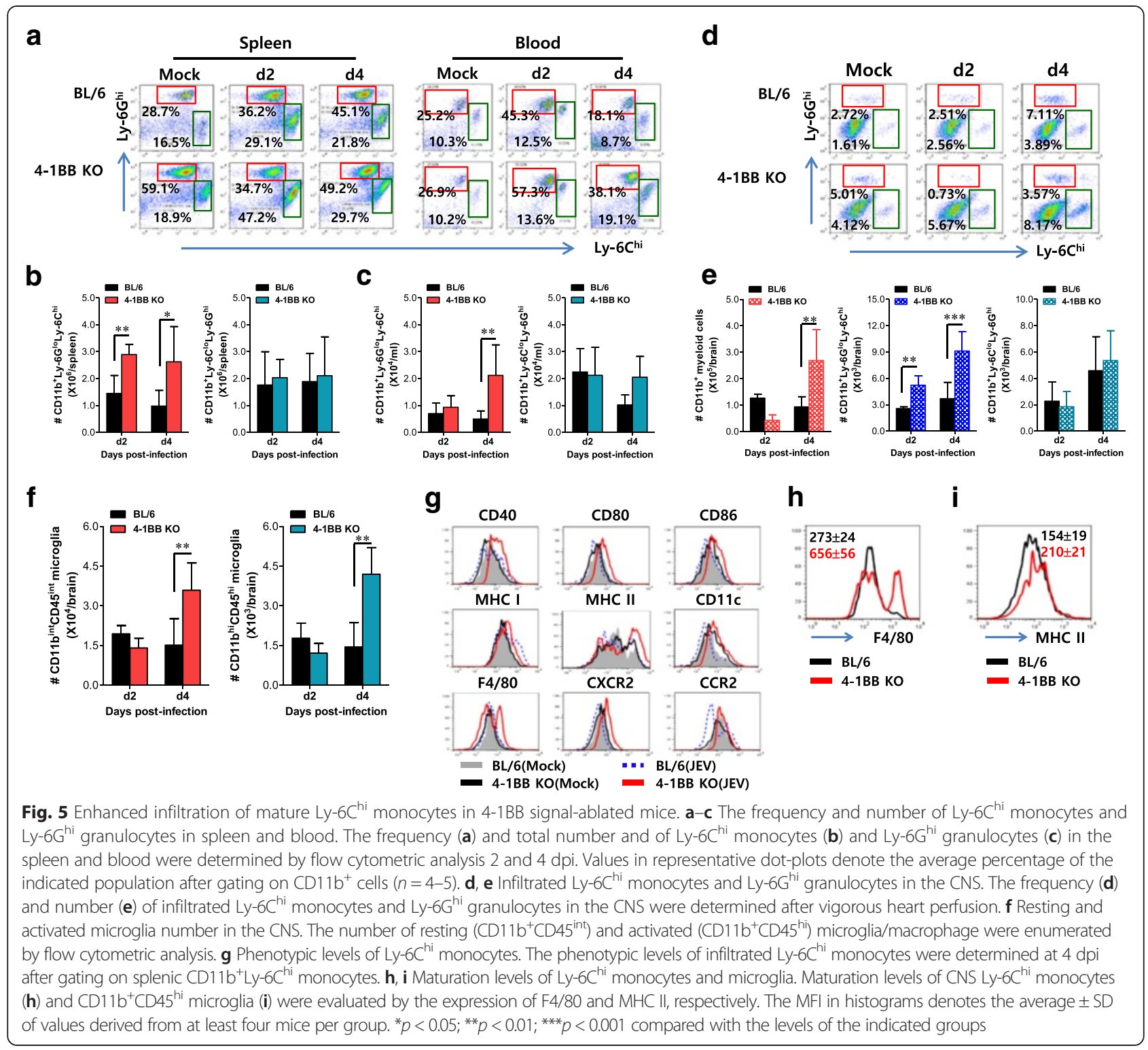

BMDC obtained from 4-1BB KO mice showed rapid induction of IFN- $\beta$ with a 30 - to 40 -fold increase in response to JEV infection compared to wild-type BMDC. Rapid and increased induction of TNF- $\alpha$ mRNA in 41BB-deficient BMDC and BMDM was also observed following JEV infection. Thus, it is likely that potent IFN-I innate responses in myeloid cells derived from 4-1BB $\mathrm{KO}$ mice may contribute to the early control of viral replication in the ablation of 4-1BB signaling.

To further characterize enhanced IFN-I innate immune responses in 4-1BB-deficient myeloid cells after JEV infection, we measured the induction levels of antiviral ISG genes. We specifically focused on PRRs (RIG-I [DDX1], MDA5 [IFITH1]) and their transcription factors (IRF3, IRF7), as well as several ISG genes (ISG49 [IFIT3], ISG54 [IFIT2], ISG56 [IFIT1]). 4-1BB-deficient
BMDC and BMDM showed differential responses of antiviral ISG expression upon JEV infection. The delayed induction of RIG-I was observed in both 4-1BB-deficient BMDC and BMDM, whereas MDA5 showed rapid induction in 4-1BB-deficient BMDC at $24 \mathrm{~h}$ after JEV infection, compared to BMDC derived from BL/6 mice (Fig. 6e). IRF3 was likely not involved in the induction of IFN-I innate responses, because IRF3 expression decreased or was not altered in JEV-infected BMDC and BMDM derived from 4-1BB-ablated mice. The expression of IRF7 was markedly higher in 4-1BB-deficient BMDC and BMDM with a delayed pattern $48 \mathrm{~h}$ after JEV infection. In addition, surprising data was obtained from the induction of ISG genes in both 4-1BB-deficient BMDC and BMDM upon JEV infection (Fig. 6f). BMDC and BMDM derived from 4-1BB KO mice showed rapid 
a

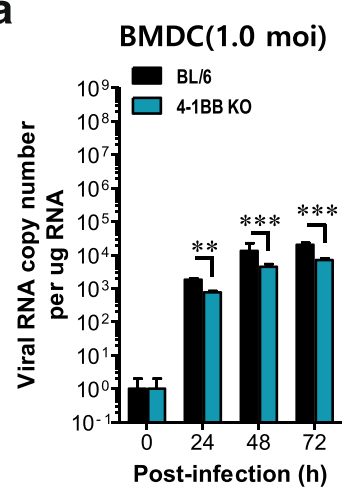

C

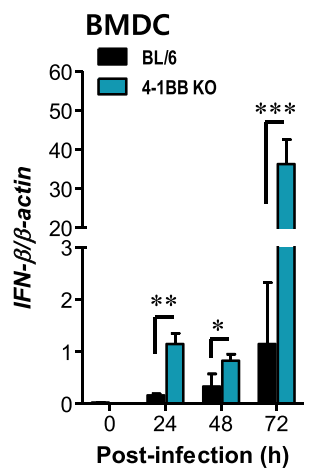

e

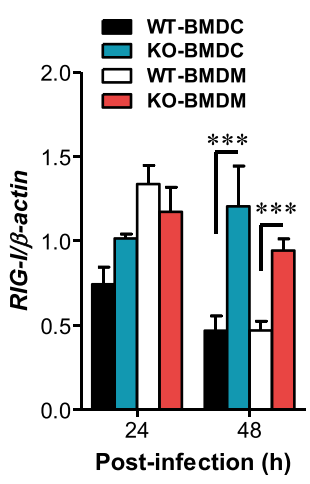

f

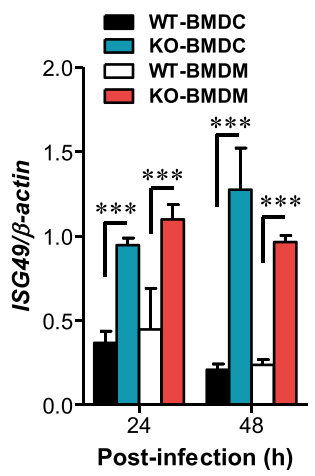

BMDC(10 moi)
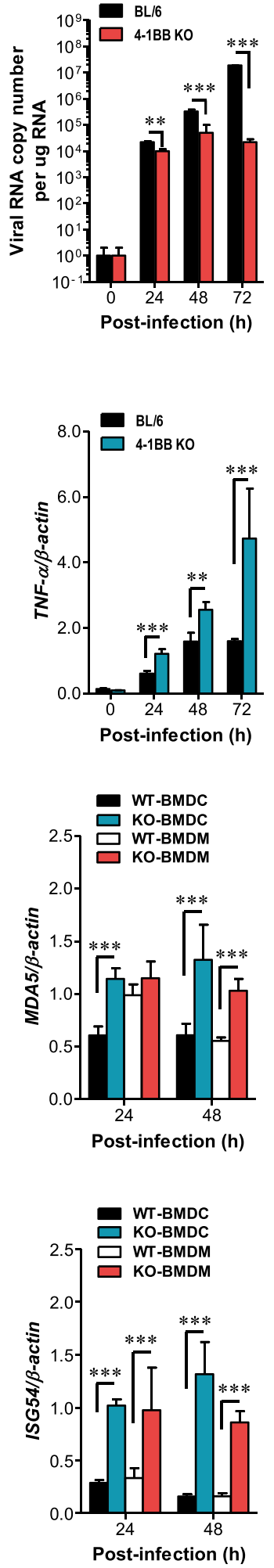

b
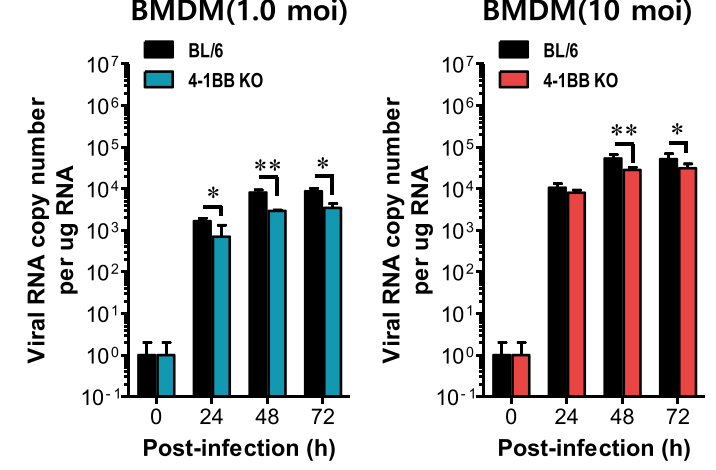

d
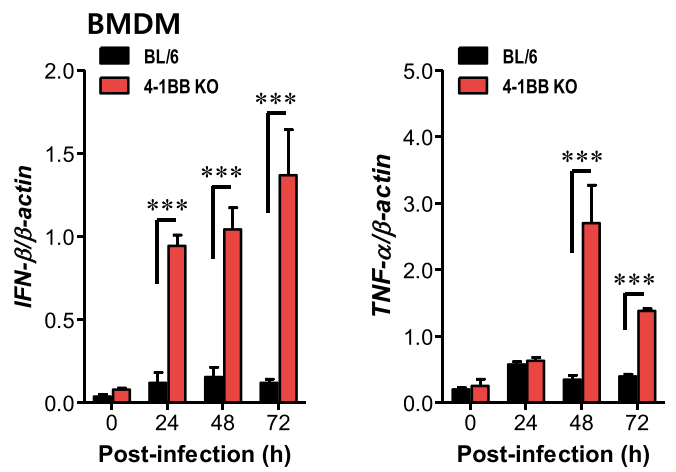
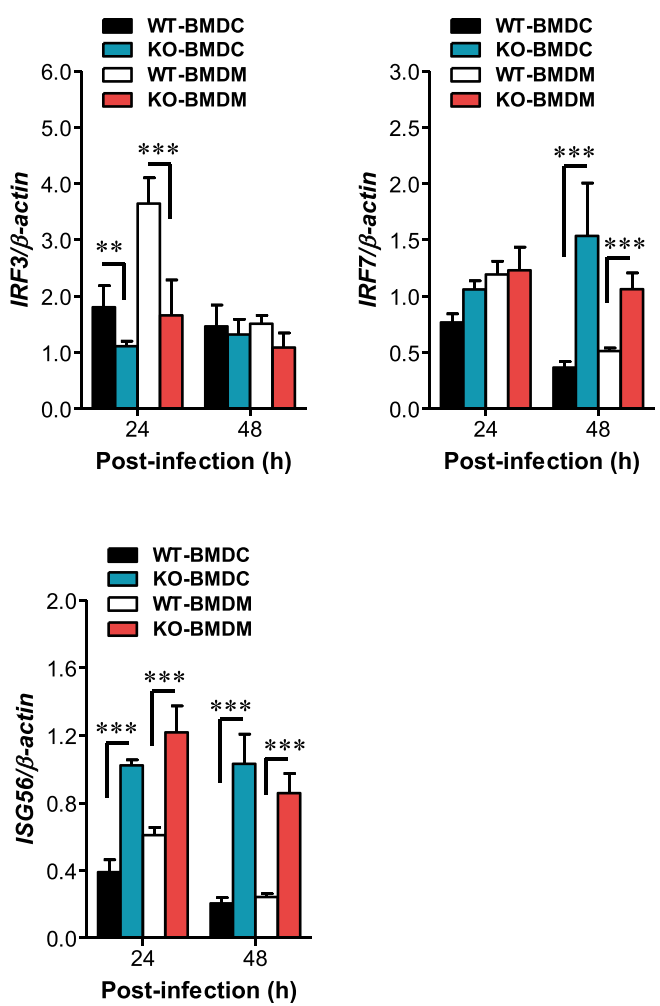

Fig. 6 (See legend on next page.) 
(See figure on previous page.)

Fig. 6 Virus control and IFN-I responses of 4-1BB signal-deficient myeloid cells to JEV infection. Primary bone marrow-derived DCs (BMDC) and macrophages (BMDM) recovered from WT and 4-1BB KO mice were infected with JEV at MOI of 1.0 and 10 for viral replication and 10 for cytokine expression. a, b JEV replication in BMDC and BMDM. c, d IFN- $\beta$ and TNF-a expression in BMDC and BMDM. e, $\mathbf{f}$ Expression of RLR, IRF, and ISG genes in BMDC and BMDM. Bar charts show the average \pm SD of values derived from BMDC and BMDM in quadruplicate. ${ }^{*} p<0.05$; ${ }^{* *} p<0.01$; ${ }^{* * *} p<0.001$ compared with the levels of the indicated groups

2- to 3-fold increases in ISG genes (ISG49, ISG54, ISG56) in response to JEV infection compared to those from BL/6 mice. Collectively, these results indicate that blocking 4-1BB signaling could stimulate rapid and increased IFN-I innate immunity responses in myeloidderived cells upon JEV infection via induction of antiviral ISG genes, thereby ameliorating JE progression by early control of viral replication.

Induction of IFN-I and ISGs in 4-1BB signal-deficient primary cortical neurons is coupled to reduction of viral replication

Neurons are the main target cell of JEV infection within the CNS, and their death is a key factor in pathogenesis and neurological sequelae [7]. Furthermore, neuron cells have been recognized to produce antiviral IFN-I in response to viral infection, helping to control viral replication $[63,64]$. Accordingly, we examined viral replication and IFN-I innate immune responses in primary cortical neuron cells generated from wild-type BL/6 and 4-1BB KO mice after JEV infection. Consistent with the results derived from myeloid-derived cells, primary cortical neurons derived from 4-1BB KO mice showed reduced JEV replication, even though neuron cells exhibited delayed control of viral replication compared to myeloidderived cells (Fig. 7a). This reduction of JEV replication in 4-1BB $\mathrm{KO}$ neurons was associated with early and increased induction of IFN-I (IFN- $\alpha / \beta)$ (Fig. 7b). In addition, the expression of antiviral ISGs in 4-1BBdeficient neurons seemed to follow IFN-I innate responses and the reduction of viral replication. Hence, the expression of PRRs (MDA5) and transcription factors (IRF3, IRF7) was observed at higher levels in 4$1 \mathrm{BB} \mathrm{KO}$ neurons compared to wild-type $\mathrm{BL} / 6$ neurons (Fig. 7c, d), even though 4-1BB KO neurons showed moderately different expression patterns of PRRs and transcription factors from those of myeloid-derived cells. Further, 4-1BB KO neurons displayed transiently higher expression of antiviral ISG genes (ISG49, ISG54, ISG56) at $24 \mathrm{~h} \mathrm{pi,} \mathrm{but} \mathrm{lower} \mathrm{levels} \mathrm{of} \mathrm{ISG49} \mathrm{and} \mathrm{ISG54}$ in 4-1BB $\mathrm{KO}$ neurons were observed $36 \mathrm{~h}$ pi compared to wild type (Fig. 7e). Collectively, these results suggest that the ablation of 4-1BB signaling could enhance IFN-I innate immune responses in neuron cells to regulate the spread of JEV in the CNS.

\section{Dominant role of 4-1BB signal-ablated HSCs in ameliorating JE}

Our results support that 4-1BB signal blockage ameliorates JE progression by providing potent antiviral IFN-I in myeloid-derived cells and early CNS infiltration of mature Ly-6C ${ }^{\text {hi }}$ monocytes. In addition, blocking the 4-1BB signal pathway facilitates the development of antiviral NK and Th1 CD4 ${ }^{+}$cells, which may contribute to early control of viral replication. $4-1 \mathrm{BB}$ is believed to be expressed primarily on activated T cells and NK cells. However, 4-1BB is also expressed by various immune cells, including neutrophils, monocytes, and macrophages [42-46]. Furthermore, expression of human 4-1BB receptor/4-1BB ligand is not restricted to immune cells, and their functions are more complex than those of mice [41]. Therefore, we sought to test which cell types, focusing on resident cells and myeloid cells derived from hematopoietic stem cells (HSCs), are dominant in the regulation of JE progression in 41BB-ablated mice. To this end, we used BM chimeric models of wild-type BL/6 and 4-1BB KO mice. Interestingly, myeloid cells derived from HSCs played a dominant role in conferring amelioration of JE in a 4-1BB-ablated environment, because wild-type $\mathrm{BL} / 6$ recipients of $4-1 \mathrm{BB}$ KO BM donor cells (KO-WT) showed enhanced resistance to JE, compared to 4-1BB KO recipient of wild-type $\mathrm{BL} / 6 \mathrm{BM}$ donors (WT-KO) and wild-type BL/6 recipients of wild-type BL/6 BM donors (WT-WT) (Fig. 8a). In addition, $\mathrm{KO}-\mathrm{WT}$ and $\mathrm{KO}-\mathrm{KO} \mathrm{BM}$ chimeric models experienced less change in body weight after JEV infection compared to other BM chimeric models (Fig. 8b). Supporting these findings, potent and rapid IFN-I innate immune responses were observed in the KO-WT BM chimeric model compared to the WT-KO BM chimeric model, based on serum IFN- $\beta$ levels (Fig. 8c). This result indicates that myeloid cells derived from 4-1BB KO HSCs play a dominant role in IFN-I innate response in 4-1BB KO hosts. Collectively, it appears that blocking 4-1BB signaling in myeloid cells derived from HSCs plays an important role in ameliorating JE by inducing potent and rapid IFN-I innate immune responses.

\section{Discussion}

The impact of the 4-1BB/4-1BBL co-stimulatory pathway on antiviral immunity has been studied in several 


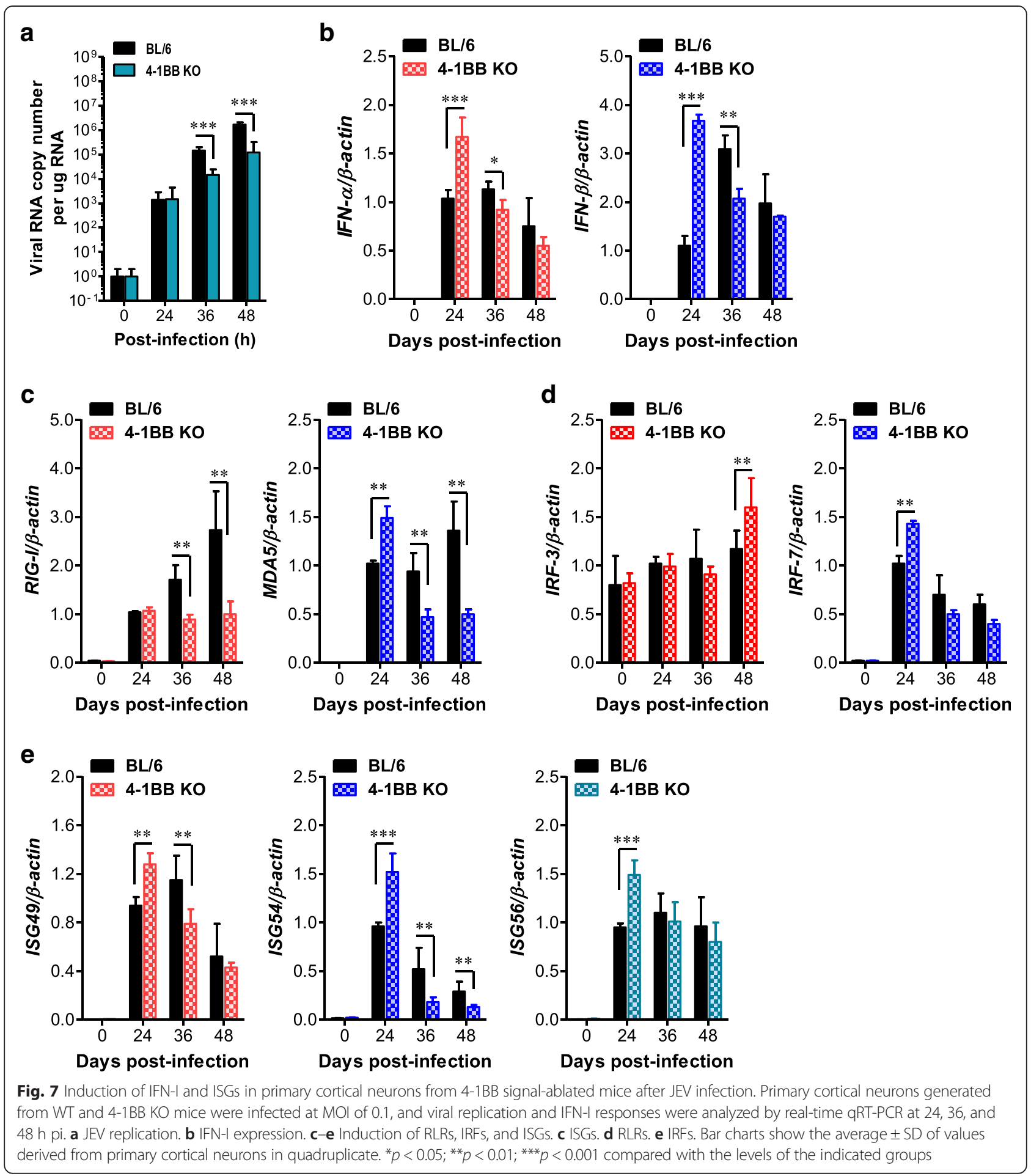

viral infection models using gene knockout systems. Although 4-1BB/4-1BBL interactions result in both positive and negative impacts on viral infection depending on the type of virus, disease severity, and timing of 41BB signal blockade [47-54], our data demonstrate that blocking the 4-1BB signaling pathway provides increased resistance to JE, rather than causing detrimental effects.
This finding is supported by our observation that treatment with a 4-1BB agonistic mAb (3E1) exacerbated JE. The reduction of viral burden in extraneural tissues and the CNS by blocking the 4-1BB signal pathway correlated with an increased frequency of IFN- $\gamma$-producing $\mathrm{NK}$ and $\mathrm{CD} 4^{+}$Th1 $\mathrm{T}$ cells as well as increased accumulation of mature $\mathrm{Ly}-6 \mathrm{C}^{\mathrm{hi}}$ monocytes in the inflamed 

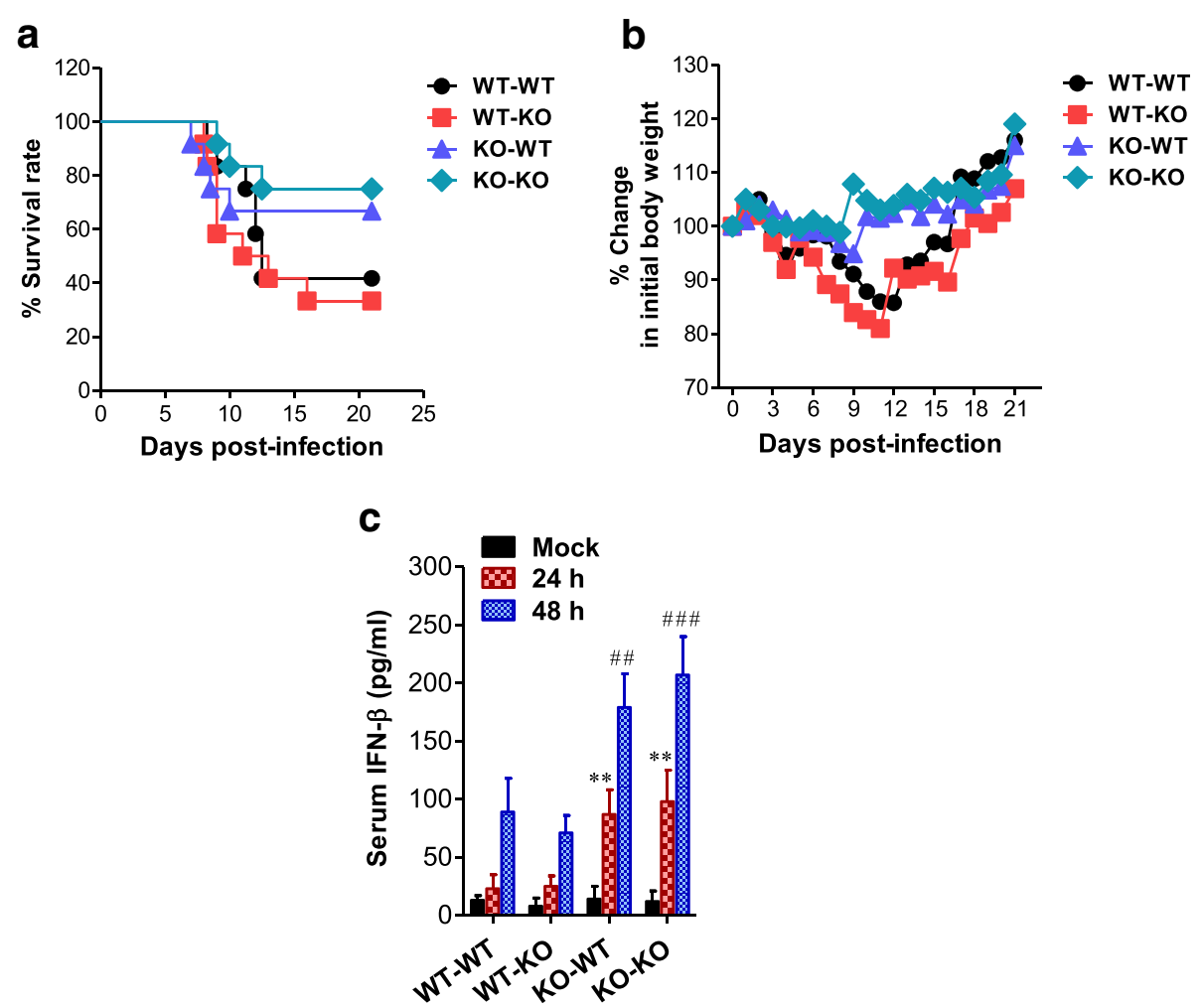

Fig. 8 Dominant role of HSCs derived from 4-1BB signal-ablated mice in ameliorating JE. BM cells from WT or 4-1BB KO mice were grafted to lethally irradiated WT or 4-1BB KO recipient mice, which were infected with JEV (3.0 $\left.\times 10^{7} \mathrm{PFU}\right)$. a Susceptibility of 4-1BB KO BM chimeric models to JE. Infected recipient mice $(n=12)$ were examined over 21 days to determine survival rate. $\mathbf{b}$ Changes in body weight. Changes in body weight are expressed as the average percentage \pm SD of body weight relative to the time of challenge. c Systemic IFN- $\beta$ levels in 4-1BB KO BM chimeras. The amount of serum IFN- $\beta$ was determined by ELISA at the indicated time points. Bar charts denote the average \pm SD of values derived from at least five BM chimeras per group. ${ }^{*} p<0.01$ compared with the levels of WT-KO BM chimera at $24 \mathrm{~h}$ pi. ${ }^{\# \#} p<0.01 ;{ }^{\# \# \#} p<0.001$ compared with the levels of WT-KO BM chimera at $48 \mathrm{~h}$ pi

CNS. More interestingly, DCs and macrophages derived from 4-1BB KO mice showed potent and rapid IFN-I innate immune responses in response to JEV infection, which could represent inhibition of JEV replication. In addition, 4-1BB signal-ablated neuron cells displayed enhanced IFN-I innate responses to JEV infection compared to normal neuron cells. Ultimately, these results imply that the promotion of IFN-I/II responses in a 4$1 \mathrm{BB}$ signal-ablated environment contribute to the inhibition of viral replication at the periphery and CNS, thereby ameliorating JE progression. Therefore, our data suggest that regulation of the 4-1BB signaling pathway with blocking $\mathrm{mAb}$ or inhibitors could represent a valuable therapeutic target in the treatment of JE.

The role of IFN- $\gamma$, the only member of IFN-II, is rather unclear in immune-mediated protection against viral disease of the CNS [65]. In particular, the requirement of IFN- $\gamma$ in recovery from infections with different flaviviruses has been shown vary. IFN- $\gamma$ plays a crucial role in early protective immune responses against a virulent North American isolate of WNV [23] and mouse-adapted strains of dengue virus $[24,25]$, but is dispensable in the control of infection with less virulent strains of WNV [26] or yellow fever virus [27, 28], and shows only a modest protective role against Murray Valley encephalitis [29]. Similarly, IL-12 has been reported to show suppressed protective immunity to JEV in mice through IFN- $\gamma$ [66], but in some experiments, IFN- $\gamma$ was associated with a beneficial effect on the outcome of JE [22]. Our data favor the latter results that show a beneficial role of IFN- $\gamma$ in JE progression. IFN$\gamma$ is involved in diverse functions for the control of microbial infections, including activation and polarization of $\mathrm{CD} 4^{+}$Th cells, upregulation of Fas in infected target cells, upregulation of MHC I- and II-restricted Ag-presentation pathways, macrophage activation, and direct antiviral activity that overlaps with activities triggered by IFN-I [67]. Conceivably, it is possible that enhanced production of IFN- $\gamma$ by NK and polyclonal CD4+ Th1 T cells in a 4-1BBblocked environment is involved in the early control of viral replication in extraneural tissues and the CNS. However, considering that NK cell-depleted mice show no change in viral burden or survival [29], NK cell responses do not appear to significantly contribute to host survival, even though infection with JEV provides early activation 
of NK cells. This notion is consistent with the absence of a protective value of NK cells against WNV [68]. Furthermore, flaviviruses, including WNV, exhibit immune escape from NK-cell attack involving the upregulation of MHC-I in infected cells [69]. Therefore, it is unlikely that IFN- $\gamma$ produced from NK cells and the cytolytic function of NK cells via granzyme B is dominant in the regulation of JE progression.

The cytolytic function of infected target cells by antigenspecific $\mathrm{CD}^{+} \mathrm{T}$ cells is thought to play a crucial role in disease recovery, given that depletion of $\mathrm{CD}^{+} \mathrm{T}$ cells results in increased viral burden in the CNS [70]. In addition, $\mathrm{CD}^{+} \mathrm{T}$ cells that show IFN- $\gamma$-producing Th1 type in response to JEV Ag appear to elicit an important protective immune parameter for the control of JEV [21]. Because of impaired and delayed JEV-specific $\mathrm{CD}^{+}$and $\mathrm{CD} 8^{+} \mathrm{T}$ cell responses in 4-1BB signal-ablated mice, our data suggest that IFN- $\gamma$-producing $\mathrm{CD} 4^{+}$Th1 cells may be dominant players in the control of viral replication during the early phase. In addition, this fact raises the notion that the equilibrium of IFN- $\gamma$-producing $\mathrm{CD}^{+}{ }^{+} \mathrm{Th} 1$ and IL-17producing $\mathrm{CD}^{+}{ }^{+}$Th17 cells may become an important parameter for prognosis in JE progression. Here, one interesting result was that the frequency or number of CD4 ${ }^{+} \mathrm{CD} 25^{+}$Foxp $3^{+}$Treg cells was not apparently changed by the ablation of 4-1BB signal. Because an increased number of $\mathrm{CD} 4^{+} \mathrm{CD} 25^{+} \mathrm{Foxp}^{+}$Treg cells is correlated with milder forms of encephalitis caused by flavivirus infection [58], this finding suggests that IFN- $\gamma$ produced from $\mathrm{CD}^{+} \mathrm{Th} 1$ cells can affect the progression of JE without changing the number of $\mathrm{CD} 4^{+} \mathrm{CD} 25^{+} \mathrm{Foxp}^{+}$Treg cells.

IFN- $\gamma$ produced by $\mathrm{CD} 4^{+}$Th1 cells appears to be involved in the maturation of myeloid-derived cells, including Ly-6C ${ }^{\text {hi }}$ monocytes [71, 72]. Further, IFN-I produced by myeloid-derived cells, including DCs and macrophages, is likely to play an important role in the differentiation and function of Ly-6Chi monocytes [73]. These notions support the increased accumulation of mature $\mathrm{CD} 11 \mathrm{~b}$ ${ }^{+}$Ly-6C ${ }^{\text {hi }}$ monocytes in both inflamed CNS and lymphoid tissues of 4-1BB KO mice via enhanced responses of IFN-II-producing NK and CD4 $4^{+}$Th1 cells and IFN-I innate responses in 4-1BB-deficient myeloid cells. In addition, activated microglia/macrophages in the CNS of 4-1BB KO mice showed higher expression levels of MHC II molecules that could be induced by IFN- $\gamma$ produced from NK and CD4 $4^{+}$Th1 cells $[61,62]$. Therefore, it is likely that mature $C D 11 b^{+} L y-6 C^{\text {hi }}$ monocytes infiltrated into the CNS of 4-1BB $\mathrm{KO}$ mice exert a more effective regulatory effect in JE progression compared to those of wild-type BL/ 6 mice. To date, the roles of CD11b $\mathrm{b}^{+} \mathrm{Ly}-6 \mathrm{C}^{\text {hi }}$ monocytes in CNS inflammation caused by neurotropic viruses have not been clearly delineated due to conflicting results [33-36]. CD11b ${ }^{+}$Ly-6C ${ }^{\text {hi }}$ monocytes cause significant damage and destruction that exacerbate morbidity and mortality [74, 75], whereas CNS infiltration of CD11b ${ }^{+}$Ly- $6 C^{\text {hi }}$ monocytes plays a protective role during CNS inflammation [33-36]. Because the enhanced infiltration of CD11b ${ }^{+}$Ly- $6 C^{\text {hi }}$ monocytes in the CNS of 4-1BB KO mice correlates with better survival, our data support their beneficial role in JE progression. Although the detailed mechanisms by which infiltrated $C D 11 b^{+} L y-6 C^{\text {hi }}$ monocytes regulate neuroinflammation caused by neurotropic viruses remain to be defined, it is thought that $\mathrm{CD} 11 \mathrm{~b}^{+} \mathrm{Ly}-$ $6 \mathrm{C}^{\mathrm{hi}}$ monocytes exert regulatory functions through differentiation into DCs, macrophages, and microglia [30-32]. In support, we found that the mature macrophage marker F4/80 was expressed in CD11b ${ }^{+}$Ly- $6 C^{\text {hi }}$ monocytes of 4$1 \mathrm{BB} \mathrm{KO}$ mice at much higher levels than in wild-type $\mathrm{BL} /$ 6 mice. In addition, ablation of the 4-1BB/4-1BBL system may enhance the anti-pathogen response by induction of myelopoiesis, resulting in the generation of more myeloid cells that can enhance the strength and efficiency of antipathogenic immune responses [76-78]. CD11b ${ }^{+} L y-6 C^{\text {hi }}$ monocytes are derived from $\mathrm{BM}$, travel through blood and subsequently arrive at inflamed tissues, depending on expression of the CCR2 chemokine receptor [30]. Thus, it is possible that $C D 11 b^{+}$Ly- $6 C^{\text {hi }}$ monocytes in a 4-1BB signalablated environment may be in greater supply in the CNS during JE progression.

The most intriguing result in this study was that DCs and macrophages derived from BM cells of 4-1BB-ablated mice showed potent and rapid IFN-I innate immune responses to JEV infection. This presumably promotes early clearance of the virus at the periphery, because DCs and macrophages are primary target cells for JEV infection. Although the detailed mechanisms behind enhanced IFN-I responses in DCs and macrophages derived from 4-1BB $\mathrm{KO}$ mice are not defined, our data suggest that the enhanced stimulation of intracellular PRRs (RIG-I, MDA5) and subsequent activation of their transcription factors (IRF7) may be involved in potent IFN-I innate immune responses in 4-1BB-deficient DCs and macrophages. In addition, the potent IFN-I response of DCs and macrophages derived from 4-1BB KO mice may be indirectly mediated by soluble factors produced from host cells by viral infection, i.e., DMAPs. We did not exclude the potential interaction of the 4-1BB signaling pathway with pathways of PRRs that recognize JEV infection in myeloid-derived cells. Considering that only a small fraction (10-20 \%) of myeloid-derived cells are infected by JEV [79], uninfected myeloid-derived cells are thought to contribute substantially to antiviral ISG induction through stimulation of IFNAR and their transcription factor STAT1, thereby inducing ISG49, ISG54, and ISG56 [80]. In addition, somewhat interestingly, neuron cells derived from 4-1BB KO mice exerted increased IFN-I innate responses. However, different induction patterns of PRRs and their transcription factors between JEV-infected neuron and myeloid-derived 
cells indicate that specific types of cells differentially trigger IFN-I innate immune responses following JEV infection. Ultimately, despite the clear induction of potent and rapid IFN-I innate immune responses in 4-1BB-deficient myeloid cells and neurons, future studies will be required to delineate the mechanistic and functional intermediates that link and regulate IFN-I innate immune responses in the absence of the 4-1BB signaling pathway.

JE pathogenesis in the murine model may be altered by the route of administration, virus propagation conditions, or strain of virus [11]. Although JEV infection via an i.p. route may not directly reflect natural infection mediated by the intradermal or subcutaneous route taken when an organism is bitten by mosquitoes, JEV introduced via an i.p. route shows entirely similar pathogenesis to a natural infection, due to peripheral amplification in the spleen. Furthermore, mice infected with JEV usually display a neurological disorder at 4-5 dpi. Thus, rapid innate immune responses, including IFN-I of myeloid cells and IFN-II of NK and $\mathrm{CD}^{+}{ }^{+}$Th1 cells, are more critical in controlling JE progression compared to delayed Agspecific adaptive responses.

\section{Conclusions}

Blocking the 4-1BB signaling pathway ameliorates JE via divergent enhancement of IFN-II-producing NK and CD4 ${ }^{+}$Th1 cells and mature Ly- $6 C^{\text {hi }}$ monocyte infiltration, as well as the IFN-I innate response of myeloidderived cells. Therefore, blocking the 4-1BB signaling pathway with antagonistic mAb or inhibitors may be a valuable therapeutic tool for the control of JE progression via enhanced IFN-I and IFN-II responses.

\section{Abbreviations \\ BBB: blood-brain barrier; BM: bone marrow; BMDC: bone marrow-derived dendritic cell; BMDM: bone marrow-derived macrophage; dpi: days post-infection; HSC: hematopoietic stem cell; IFN-I/II: type I/II interferon; JE: Japanese encephalitis; KO: knockout; TLR: Toll-like receptor; TNFR: tumor necrosis factor receptor.}

\section{Competing interests}

The authors declare that they have no competing interests.

\section{Authors' contributions}

SBK and SKE designed and analyzed the results and wrote the manuscript. SBK, JYC, JHK, EU, AMP, and YWH conducted the experiments. SYP, JHL, and KK contributed reagents/materials/analysis tools. All authors read and approved the final manuscript.

\section{Acknowledgements}

This study was supported by the National Research Foundation of Korea (NRF) grant funded by the Korean Government (MISP) (2013R1A4A1069486). The funder had no role in study design, data collection and analysis, decision to publish, or preparation of the manuscript.

\footnotetext{
Author details

${ }^{1}$ College of Veterinary Medicine and Bio-Safety Research Institute, Chonbuk National University, Iksan 54596, Republic of Korea. ${ }^{2}$ Department of Bioactive Material Sciences, Graduate School, Chonbuk National University, Jeonju 54896, Republic of Korea. ${ }^{3}$ Department of Pharmacology, School of Medicine, Pusan National University, Yangsan 50612, Republic of Korea.
}

Received: 2 October 2015 Accepted: 16 November 2015

Published online: 24 November 2015

\section{References}

1. Kuiken T, Leighton FA, Fouchier RA, LeDuc JW, Peiris JS, Schudel A, et al. Public health. Pathogen surveillance in animals. Science. 2005;309:1680-1. doi:10.1126/science.1113310.

2. Le Flohic G, Porphyre V, Barbazan P, Gonzalez JP. Review of climate, landscape, and viral genetics as drivers of the Japanese encephalitis virus ecology. PLoS Negl Trop Dis. 2013;7, e2208. doi:10.1371/journal.pntd.0002208.

3. Daep CA, Munoz-Jordan JL, Eugenin EA. Flaviviruses, an expanding threat in public health: focus on dengue, West Nile, and Japanese encephalitis virus. J Neurovirol. 2014;20:539-60. doi:10.1007/s13365-014-0285-z.

4. Center for Disease. Japanese encephalitis surveillance and immunization-Asia and the Western pacific. MMWR Morb Mortal Wkly Rep. 2013;62:658-62.

5. Center for Disease. West Nile Virus activity-Human disease cases reported. 2005-2009. 2009. http://www.cdc.gov/ncidod/dvbid/westnile/. Accessed 4 Sept 2014.

6. Yun SI, Song BH, Kim JK, Yun GN, Lee EY, Li L, et al. A molecularly cloned, live-attenuated Japanese encephalitis vaccine SA14-14-2 virus: a conserved single amino acid in the ij hairpin of the viral $\mathrm{E}$ glycoprotein determines neurovirulence in mice. PLoS Pathog. 2014;10, e1004290. doi:10. 1371/journal.ppat.1004290.

7. Sips GJ, Wilschut J, Smit JM. Neuroinvasive flavivirus infections. Rev Med Virol. 2012;22:69-87. doi:10.1002/rmv.712.

8. Wilson MR. Emerging viral infections. Curr Opin Neurol. 2013;26:301-6. doi:10.1097/WCO.0b013e328360dd2b.

9. Chen CJ, Ou YC, Lin SY, Raung SL, Liao SL, Lai CY, et al. Glial activation involvement in neuronal death by Japanese encephalitis virus infection. J Gen Virol. 2010;91:1028-37. doi:10.1099/vir. 0.013565-0.

10. Ghoshal A, Das S, Ghosh S, Mishra MK, Sharma V, Koli P, et al. Proinflammatory mediators released by activated microglia induces neuronal death in Japanese encephalitis. Glia. 2007;55:483-96. doi:10.1002/glia.20474.

11. Ghosh D, Basu A. Japanese encephalitis — a pathological and clinical perspective. PLoS Negl Trop Dis. 2009;3, e437. doi:10.1371/journal.pntd.0000437.

12. Le Bon A, Tough DF. Links between innate and adaptive immunity via type I interferon. Curr Opin Immunol. 2002;14:432-6.

13. Wang BX, Fish EN. The yin and yang of viruses and interferons. Trends Immunol. 2012;33:190-7. doi:10.1016/j.it.2012.01.004.

14. Welsh RM, Bahl K, Marshall HD, Urban SL. Type 1 interferons and antiviral CD8 T-cell responses. PLoS Pathog. 2012;8, e1002352. doi:10.1371/journal. ppat.1002352.

15. Paun A, Pitha PM. The innate antiviral response: new insights into a continuing story. Adv Virus Res. 2007;69:1-66. doi:10.1016/S0065-3527(06)69001-5.

16. Suthar MS, Ma DY, Thomas S, Lund JM, Zhang N, Daffis S, et al. IPS-1 is essential for the control of West Nile virus infection and immunity. PLoS Pathog. 2010;6, e1000757. doi:10.1371/ journal.ppat.1000757.

17. Lazear HM, Lancaster A, Wilkins C, Suthar MS, Huang A, Vick SC, et al. IRF-3, IRF-5, and IRF-7 coordinately regulate the type I IFN response in myeloid dendritic cells downstream of MAVS signaling. PLOS Pathog. 2013;9, e1003118. doi:10.1371/journal.ppat.1003118.

18. Loo YM, Fornek J, Crochet N, Bajwa G, Perwitasari O, Martinez-Sobrido L, et al Distinct RIG-I and MDA5 signaling by RNA viruses in innate immunity. J Virol. 2008:82:335-45. doi:10.1128/JVl. 01080-07.

19. Brennan K, Bowie AG. Activation of host pattern recognition receptors by viruses. Curr Opin Microbiol. 2010;13:503-7. doi:10.1016/j.mib.2010.05.007.

20. Manocha GD, Mishra R, Sharma N, Kumawat KL, Basu A, Singh SK. Regulatory role of TRIM21 in the type I interferon pathway in Japanese encephalitis virus-infected human microglial cells. J Neuroinflammation. 2014;11:24. doi:10.1186/1742-2094-11-24.

21. Kumar P, Sulochana P, Nirmala G, Chandrashekar R, Haridattatreya M, Satchidanandam V. Impaired T helper 1 function of nonstructural protein 3specific T cells in Japanese patients with encephalitis with neurological sequelae. J Infect Dis. 2004;189:880-91. doi:10.1128/JVI.00274-06.

22. Larena M, Regner M, Lobigs M. Cytolytic effector pathways and IFN-gamma help protect against Japanese encephalitis. Eur J Immunol. 2013;43:1789-98. doi:10.1371/journal.pntd.0001449.

23. Shrestha B, Wang T, Samuel MA, Whitby K, Craft J, Fikrig E, Gamma interferon plays a crucial early antiviral role in protection against West Nile virus infection. J Virol. 2006;80:5338-48. 
24. Fagundes CT, Costa W, Cisalpino D, Amaral FA, Souza PR, Souza RS, et al. IFNgamma production depends on IL-12 and IL-18 combined action and mediates host resistance to dengue virus infection in a nitric oxide-dependent manner. PLoS Negl Trop Dis. 2011;5, e1449. doi:10.1099/vir.0.81306-0.

25. Shresta S, Kyle JL, Snider HM, Basavapatna M, Beatty PR, Harris E. Interferon-dependent immunity is essential for resistance to primary dengue virus infection in mice, whereas T- and B-cell-dependent immunity are less critical. J Virol. 2004:78:2701-10. doi:10.1128/JVI. 75.5.2107-2118.2001.

26. Wang $Y$, Lobigs M, Lee E, Koskinen A, Mullbacher A. CD8(+) T cell-mediated immune responses in West Nile virus (Sarafend strain) encephalitis are independent of gamma interferon. J Gen Virol. 2006;87:3599-609. doi:10.1371/journal.ppat.1000614.

27. Liu T, Chambers TJ. Yellow fever virus encephalitis: properties of the brain-associated T-cell response during virus clearance in normal and gamma interferon-deficient mice and requirement for CD4+ lymphocytes. J Virol. 2001;75:2107-18.

28. Meier KC, Gardner CL, Khoretonenko MV, Klimstra WB, Ryman KD. A mouse model for studying viscerotropic disease caused by yellow fever virus infection. PLoS Pathog. 2009;5, e1000614. doi:10.1086/381768.

29. Lobigs M, Mullbacher A, Wang Y, Pavy M, Lee E. Role of type I and type II interferon responses in recovery from infection with an encephalitic flavivirus. J Gen Virol. 2003;84:567-72. doi:10.1002/eji.201243152.

30. Terry RL, Getts DR, Deffrasnes C, van Vreden C, Campbell IL, King NJ. Inflammatory monocytes and the pathogenesis of viral encephalitis. J Neuroinflammation. 2012;9:270. doi:10.1186/ 1742-2094-9-270.

31. Getts DR, Terry RL, Getts MT, Muller M, Rana S, Shrestha B, et al. Ly6c + "inflammatory monocytes" are microglial precursors recruited in a pathogenic manner in West Nile virus encephalitis. J Exp Med. 2008;205:2319-37. doi:10.1084/jem.20080421.

32. Ginhoux F, Greter M, Leboeuf M, Nandi S, See P, Gokhan S, et al. Fate mapping analysis reveals that adult microglia derive from primitive macrophages. Science. 2010;330:841-5. doi:10.1126/ science.1194637.

33. Lim JK, Obara CJ, Rivollier A, Pletnev AG, Kelsall BL, Murphy PM. Chemokine receptor Ccr2 is critical for monocyte accumulation and survival in West Nile virus encephalitis. J Immunol. 2011;186:471-8. doi:10.4049/jimmunol.1003003.

34. Ben-Nathan D, Huitinga I, Lustig S, van Rooijen N, Kobiler D. West Nile virus neuroinvasion and encephalitis induced by macrophage depletion in mice. Arch Virol. 1996;141:459-69.

35. lijima N, Mattei LM, Iwasaki A. Recruited inflammatory monocytes stimulate antiviral Th1 immunity in infected tissue. Proc Natl Acad Sci U S A. 2011;108: 284-9. doi:10.1073/ pnas.1005201108.

36. Chen BP, Kuziel WA, Lane TE. Lack of CCR2 results in increased mortality and impaired leukocyte activation and trafficking following infection of the central nervous system with a neurotropic coronavirus. J Immunol. 2001; 167:4585-92.

37. Denney L, Kok WL, Cole SL, Sanderson S, McMichael AJ, Ho LP. Activation of invariant NKT cells in early phase of experimental autoimmune encephalomyelitis results in differentiation of Ly6Chi inflammatory monocyte to M2 macrophages and improved outcome. J Immunol. 2012; 189:551-7. doi:10.4049/jimmunol.1103608.

38. Hesske L, Vincenzetti C, Heikenwalder M, Prinz M, Reith W, Fontana A, et al. Induction of inhibitory central nervous system-derived and stimulatory blood-derived dendritic cells suggests a dual role for granulocytemacrophage colony-stimulating factor in central nervous system inflammation. Brain. 2010;133:1637-54. doi:10.1093/brain/awq081.

39. Ifergan I, Kebir H, Bernard M, Wosik K, Dodelet-Devillers A, Cayrol R, et al. The blood-brain barrier induces differentiation of migrating monocytes into Th17polarizing dendritic cells. Brain. 2008;131:785-99. doi:10.1093/brain/awm295.

40. Rezai-Zadeh K, Gate D, Town T. CNS infiltration of peripheral immune cells: D-Day for neurodegenerative disease? J Neuroimmune Pharmacol. 2009;4: 462-75. doi:10.1007/ s11481-009-9166-2.

41. Wortzman ME, Clouthier DL, McPherson AJ, Lin GH, Watts TH. The contextual role of TNFR family members in CD8(+) T-cell control of viral infections. Immunol Rev. 2013;255:125-48. doi:10.1111/imr.12086.

42. Futagawa T, Akiba H, Kodama T, Takeda K, Hosoda Y, Yagita H, et al. Expression and function of 4-1BB and 4-1BB ligand on murine dendritic cells. Int Immunol. 2002;14:275-86.

43. Melero I, Johnston JV, Shufford WW, Mittler RS, Chen L. NK1.1 cells express 4-1BB (CDw137) costimulatory molecule and are required for tumor immunity elicited by anti-4-1BB monoclonal antibodies. Cell Immunol. 1998;190:167-72. doi:10.1006/cimm.1998.1396.
44. Lee SC, Ju SA, Sung BH, Heo SK, Cho HR, Lee EA, et al. Stimulation of the molecule 4-1BB enhances host defense against Listeria monocytogenes infection in mice by inducing rapid infiltration and activation of neutrophils and monocytes. Infect Immun. 2009:77:2168-76. doi:10.1128/IAI. 01350-08.

45. Wang Q, Zhang P, Zhang Q, Wang X, Li J, Sun W, et al. Analysis of CD137 and CD137L expression in human primary tumor tissues. Croat Med J. 2008:49:192-200.

46. Choi BK, Kim YH, Lee DG, Oh HS, Kim KH, Park SH, et al. In vivo 4-1BB deficiency in myeloid cells enhances peripheral T cell proliferation by increasing IL-15. J Immunol. 2015;194:1580-90. doi:10.4049/jimmunol.1303439.

47. Halstead ES, Mueller YM, Altman JD, Katsikis PD. In vivo stimulation of CD137 broadens primary antiviral CD8+ T cell responses. Nat Immunol. 2002;3:536-41. doi:10.1038/ni798.

48. Munks MW, Mourich DV, Mittler RS, Weinberg AD, Hill AB. 4-1BB and OX40 stimulation enhance CD8 and CD4 T-cell responses to a DNA prime, poxvirus boost vaccine. Immunology. 2004;112:559-66. doi:10.1111/j.1365-2567.2004.01917.x.

49. Tan JT, Whitmire JK, Ahmed R, Pearson TC, Larsen CP. 4-1BB ligand, a member of the TNF family, is important for the generation of antiviral CD8 T cell responses. J Immunol. 1999;163:4859-68.

50. Hendriks J, Xiao Y, Rossen JW, van der Sluijs KF, Sugamura K, Ishii N, et al. During viral infection of the respiratory tract, CD27, 4-1BB, and OX40 collectively determine formation of CD8+ memory $T$ cells and their capacity for secondary expansion. J Immunol. 2005;175:1665-76.

51. Lin GH, Sedgmen BJ, Moraes TJ, Snell LM, Topham DJ, Watts TH, et al. Endogenous 4-1BB ligand plays a critical role in protection from influenzainduced disease. J Immunol. 2009:182:934-47.

52. Foell J, Strahotin S, O'Neil SP, McCausland MM, Suwyn C, Haber M, et al. CD137 costimulatory $T$ cell receptor engagement reverses acute disease in lupus-prone NZB x NZW F1 mice. J Clin Invest. 2003;111:1505-18. doi:10.1172/JCI17662.

53. Seo SK, Choi JH, Kim YH, Kang WJ, Park HY, Suh JH, et al. 4-1BB-mediated immunotherapy of rheumatoid arthritis. Nat Med. 2004;10:1088-94. doi:10.1038/nm1107.

54. Foell JL, Diez-Mendiondo BI, Diez OH, Holzer U, Ruck P, Bapat AS, et al. Engagement of the CD137 (4-1BB) costimulatory molecule inhibits and reverses the autoimmune process in collagen-induced arthritis and establishes lasting disease resistance. Immunology. 2004;113:89-98. doi:10.1111/ j.1365-2567.2004.01952.x.

55. Frentsch M, Arbach O, Kirchhoff D, Moewes B, Worm M, Rothe M, et al. Direct access to CD4+ T cells specific for defined antigens according to CD154 expression. Nat Med. 2005;11:1118-24. doi:10.1038/nm1292.

56. Chattopadhyay PK, Yu J, Roederer M. Live-cell assay to detect antigenspecific CD4+ T-cell responses by CD154 expression. Nat Protoc. 2006;1:1-6. doi:10.1038/nprot.2006.1.

57. Schwarz H. Biological activities of reverse signal transduction through CD137 ligand. J Leukoc Biol. 2005;77:281-6. doi:10.1189/jlb.0904558.

58. Lanteri MC, O'Brien KM, Purtha WE, Cameron MJ, Lund JM, Owen RE, et al. Tregs control the development of symptomatic West Nile virus infection in humans and mice. J Clin Invest. 2009;119:3266-77. doi:10.1172/JCl39387.

59. Kim YH, Choi BK, Shin SM, Kim CH, Oh HS, Park SH, et al. 4-1BB triggering ameliorates experimental autoimmune encephalomyelitis by modulating the balance between Th17 and regulatory T cells. J Immunol. 2011;187: 1120-8. doi:10.4049/jimmunol.1002681.

60. Ford AL, Foulcher E, Lemckert FA, Sedgwick JD. Microglia induce CD4 T lymphocyte final effector function and death. J Exp Med. 1996;184:1737-45.

61. Ebner F, Brandt C, Thiele P, Richter D, Schliesser U, Siffrin V, et al. Microglial activation milieu controls regulatory T cell responses. J Immunol. 2013;191: 5594-602. doi:10.4049/jimmunol.1203331.

62. Noailles A, Fernandez-Sanchez L, Lax P, Cuenca N. Microglia activation in a model of retinal degeneration and TUDCA neuroprotective effects. J Neuroinflammation. 2014;11:186. doi:10.1186/s12974-014-0186-3.

63. Delhaye S, Paul S, Blakqori G, Minet M, Weber F, Staeheli P, et al. Neurons produce type I interferon during viral encephalitis. Proc Natl Acad Sci U S A. 2006;103:7835-40. doi:10.1073/pnas.0602460103.

64. Minter MR, Main BS, Brody KM, Zhang M, Taylor JM, Crack PJ. Soluble amyloid triggers a myeloid differentiation factor 88 and interferon regulatory factor 7 dependent neuronal type-1 interferon response in vitro. J Neuroinflammation. 2015;12:71. doi:10.1186/s12974-015-0263-2.

65. Griffin DE, Metcalf T. Clearance of virus infection from the CNS. Curr Opin Virol. 2011;1:216-21. doi:10.1016/j.coviro.2011.05.021. 
66. Chen HW, Pan $\mathrm{CH}$, Huan HW, Liau MY, Chiang JR, Tao MH. Suppression of immune response and protective immunity to a Japanese encephalitis virus DNA vaccine by coadministration of an IL-12-expressing plasmid. J Immunol. 2001;166:7419-26.

67. Lin FC, Young HA. Interferons: success in anti-viral immunotherapy. Cytokine Growth Factor Rev. 2014;25:369-76. doi:10.1016/j.cytogfr.2014.07.015.

68. Shrestha B, Samuel MA, Diamond MS. CD8+ T cells require perforin to clear West Nile virus from infected neurons. J Virol. 2006;80:119-29. doi:10.1128/ JVI.80.1.119-129.2006

69. Lobigs M, Mullbacher A, Regner M. MHC class I up-regulation by flaviviruses: immune interaction with unknown advantage to host or pathogen. Immunol Cell Biol. 2003;81:217-23. doi:10.1046/j.1440-1711.2003.01161.x.

70. Larena $M$, Regner $M$, Lee $E$, Lobigs M. Pivotal role of antibody and subsidiary contribution of CD8+ T cells to recovery from infection in a murine model of Japanese encephalitis. J Virol. 2011;85:5446-55. doi:10. 1128/JVI.02611-10.

71. Eljaafari A, Li YP, Miossec P. IFN-gamma, as secreted during an alloresponse, induces differentiation of monocytes into tolerogenic dendritic cells, resulting in FoxP3+ regulatory T cell promotion. J Immunol. 2009;183:2932-45. doi:10. 4049/jimmunol.0804352.

72. Kerkar SP, Chinnasamy D, Hadi N, Melenhorst J, Muranski P, Spyridonidis A, et al. Timing and intensity of exposure to interferon-gamma critically determines the function of monocyte-derived dendritic cells. Immunology. 2014;143:96-108. doi:10.1111/imm.12292.

73. Lee PY, Li Y, Kumagai Y, Xu Y, Weinstein JS, Kellner ES, et al. Type I interferon modulates monocyte recruitment and maturation in chronic inflammation. Am J Pathol. 2009;175:2023-33. doi:10.2353/ajpath.2009.090328.

74. Izikson L, Klein RS, Charo IF, Weiner HL, Luster AD. Resistance to experimental autoimmune encephalomyelitis in mice lacking the CC chemokine receptor (CCR)2. J Exp Med. 2000;192:1075-80.

75. Fife BT, Huffnagle GB, Kuziel WA, Karpus WJ. CC chemokine receptor 2 is critical for induction of experimental autoimmune encephalomyelitis. J Exp Med. 2000;192:899-905.

76. Jiang D, Chen Y, Schwarz H. CD137 induces proliferation of murine hematopoietic progenitor cells and differentiation to macrophages. J Immunol. 2008;181:3923-32.

77. Jiang D, Yue PS, Drenkard D, Schwarz H. Induction of proliferation and monocytic differentiation of human CD34+ cells by CD137 ligand signaling. Stem Cells. 2008:26:23722381. doi:10.1634/stemcells.2008-0158.

78. Lee SW, Park Y, So T, Kwon BS, Cheroutre H, Mittler RS, et al. Identification of regulatory functions for 4-1BB and 4-1BBL in myelopoiesis and the development of dendritic cells. Nat Immunol. 2008;9:917-26. doi:10.1038/ni. 1632.

79. Aleyas AG, Han YW, Patil AM, Kim SB, Kim K, Eo SK. Impaired crosspresentation of CD8alpha + CD11C + dendritic cells by Japanese encephalitis virus in a TLR2/MyD88 signal pathway-dependent manner. Eur J Immunol. 2012;42:2655-66. doi:10.1002/eji.201142052.

80. Han YW, Choi JY, Uyangaa E, Kim SB, Kim JH, Kim BS, et al. Distinct dictation of Japanese encephalitis virus-induced neuroinflammation and lethality via triggering TLR3 and TLR4 signal pathways. PLoS Pathog. 2014;10, e1004319. doi:10.1371/journal.ppat.1004319.

\section{Submit your next manuscript to BioMed Central and we will help you at every step:}

- We accept pre-submission inquiries

- Our selector tool helps you to find the most relevant journal

- We provide round the clock customer support

- Convenient online submission

- Thorough peer review

- Inclusion in PubMed and all major indexing services

- Maximum visibility for your research

Submit your manuscript at www.biomedcentral.com/submit
C) Biomed Central 